\title{
A Methodological Framework for Assessing the Sustainability of Solid Biofuels Systems
}

\author{
Julio C. Sacramento Rivero ${ }^{1} \cdot$ Tuyeni H. Mwampamba ${ }^{2}$. Freddy S. Navarro-Pineda ${ }^{1} \cdot$ Ricardo Musule $^{3,4}$. \\ Carlos A. García ${ }^{3} \cdot$ René D. Martínez-Bravo ${ }^{2}$ - Ana L. Morales-García ${ }^{2} \cdot$ Mintzirani Equihua-Sánchez $^{3}$. \\ Alfredo F. Fuentes-Gutiérrez ${ }^{2} \cdot$ Rosa M. Gallardo-Álvarez ${ }^{3}$. César R. Ruiz Camou ${ }^{3}$. Genice K. Grande-Acosta ${ }^{5}$. \\ Fabio Manzini ${ }^{5}$. Jorge M. Islas-Samperio ${ }^{4} \cdot$ Rafael Camarillo $^{3}$
}

Received: 20 May 2021 / Accepted: 24 November 2021 / Published online: 28 January 2022

(c) The Author(s), under exclusive licence to Springer Science+Business Media, LLC, part of Springer Nature 2021

\begin{abstract}
This paper introduces a methodological framework for assessing the sustainability of solid biofuels in Mexico. The designed framework comprises 13 normalized indicators and two diagnostic studies, covering the economic, social, environmental, and institutional sustainability dimensions, and their intersections. Indicators are normalized using the concept of load capacity of a system, similarly to the planetary boundaries. Thus, the graphical representation of results facilitates their multidimensional analysis. The framework was applied to three case studies: traditional fuelwood in rural households, charcoal for restaurant grilling, and electricity cogeneration from sugarcane bagasse. This was part of an iterative process of testing and refining the framework and simultaneously demonstrating its application in the Mexican bioenergy context. This led to the conclusion that the resulting framework (a) provides a useful, quantitative, and comprehensive overview of both broad and specific sustainability aspects of the assessed system; (b) requires a balance of accessible but also scattered or sensitive data, similarly to most existing frameworks; (c) is highly flexible and applicable to both modern and traditional solid biofuels; and (d) is simple to communicate and interpret for a wide audience. Key directions for improvement of the framework are also discussed.
\end{abstract}

Keywords Sustainability indicators $\cdot$ Sustainability assessment $\cdot$ Mexico $\cdot$ Charcoal $\cdot$ Sugarcane bagasse $\cdot$ Fuelwood

$\begin{array}{ll}\text { Abbreviations } \\ \text { BCR } & \text { Benefit-cost ratio } \\ \text { BID } & \text { Biodiversity impact diagnosis } \\ \text { COD } & \text { Chemical oxygen demand } \\ \text { COe } & \text { Carbon monoxide emissions } \\ \text { EARN } & \text { Average earnings per capita }\end{array}$

Freddy S. Navarro-Pineda

freddy.navarro@correo.uady.mx

1 Facultad de Ingeniería Química, Universidad Autónoma de Yucatán, Mérida, Mexico

2 Instituto de Investigaciones en Ecosistemas y Sustentabilidad, Universidad Nacional Autónoma de México, Mexico City, Mexico

3 Escuela Nacional de Estudios Superiores, Universidad Nacional Autónoma de México, Mexico City, Mexico

4 Facultad de Ciencias Químicas, Universidad Veracruzana campus Coatzacoalcos, Coatzacoalcos, Mexico

5 Instituto de Energías Renovables, Universidad Nacional Autónoma de México, Mexico City, Mexico

$\begin{array}{ll}\text { EDIR } & \text { Direct employment } \\ \text { EDU } & \text { Educational level of WORKERS } \\ \text { EFORM } & \text { Formal Employment } \\ \text { EGEN } & \text { Gender equality among employees } \\ \text { EROI } & \text { Energy return on investment } \\ \text { FER } & \text { Fossil energy ratio } \\ \text { FMP } & \text { Forest management plan } \\ \text { GHG } & \text { Greenhouse gases } \\ \text { GHGm } & \text { Mitigation of GHG emissions } \\ \text { GWP } & \text { Global-warming potential } \\ \text { ISD } & \text { Institutional sustainability diagnosis } \\ \text { LCA } & \text { Life cycle assessment } \\ \text { LPG } & \text { Liquefied-petroleum gas } \\ \text { MCDA } & \text { Multi-Criteria Decision Analysis } \\ \text { MPL } & \text { Maximum permissible level } \\ \text { nBCR } & \text { Normalized benefit-cost ratio } \\ \text { nEROI } & \text { Normalized energy return on investment } \\ \text { nFER } & \text { Normalized fossil energy ratio } \\ \text { PM } & \text { Particulate matter } \\ \text { PMe } & \text { Particulate matter emissions }\end{array}$




$\begin{array}{ll}\text { PV } & \text { Present value } \\ \text { SBC } & \text { Solid Biofuels Cluster } \\ \text { SB } & \text { Solid biofuels } \\ \text { SDG } & \text { Sustainable development goal } \\ \text { SI } & \text { Supplementary information } \\ \text { TN } & \text { Total nitrogen } \\ \text { WEUT } & \text { Contribution to water eutrophication } \\ \text { WHO } & \text { World Health Organization } \\ \text { WINT } & \text { Water intensity }\end{array}$

\section{Introduction}

The use of forest and agro-industrial biomass for energy production is expected to grow, especially in developing countries, mainly due to the versatility of solid biofuels [1]. Solid biofuels (SBs) are expected to contribute a significant proportion of total global primary energy consumption in the near future. The International Renewable Energy Agency foresees that for achieving the $1.5^{\circ} \mathrm{C}$ goal against climate change, the share of modern biomass in the world's energy consumption needs to grow from a current 3 to $18 \%$ for heating by 2050. Similarly, the share of electricity from renewables would need to grow from 25 to $90 \%$ by 2050 [2]. Beyond the obvious benefits of wood-based energy such as its renewability and reduced carbon footprint, the broader sustainability of these systems has been widely questioned, especially that of large-scale systems [3]. Quantifying and characterizing the sustainability of current biomass management practices is needed to better understand the social, environmental, and economic implications of promoting solid biofuels [4].

In Mexico, the Solid Biofuels Cluster (SBC) of the Mexican Center for Bioenergy Innovation (CEMIEBio) is the largest, most important interinstitutional academic research project focused on SBs, gathering the expressed needs from the public and private sectors, as well as academia and government. One strategic research line of the SBC had the main objective of proposing a streamlined method to assess the sustainability of current and new SB pathways in Mexico. From the outset of the SBC project, the following were identified as desirable features of the assessment framework: (1) capable of measuring current performance with respect to well-defined and objective targets, (2) serve as a tool of continuous improvement by choosing key indicators that can reflect significant changes over a short time span, (3) capable of comparing several types of feedstock sources and end-uses of SB using the same framework, (4) include information on the social, environmental, economic, and institutional dimensions of sustainability, and their intersections.

Several initiatives exist to promote sustainability of bioenergy. The European Union Renewable Energy Directive (EU-RED) and the United States-Renewable Fuel Standard
(US-RFS2) are examples of laws and regulations that set the sustainability expectations for the industry. Voluntary certification schemes such as the Roundtable on Sustainable Biomaterials (RSB) and the International Sustainability and Carbon Certification (ISCC) also set standards. There are also many institutional and academic proposals, which have been analyzed in several reviews $[3,5,6]$. A systematic search was made to identify the most relevant work related to the objective of this work; it included scientific articles and reviews published in Spanish and English between the years 2000 and 2019. The searched databases were Scopus, Scielo, and Google Scholar. The keywords used for the search and their respective combinations were as follows: "bioenergy," "solid biofuel," "sustainability assessment," and "sustainability analysis," in English and Spanish. The criterion for refining the number of papers found consisted in selecting the research papers that had as a main objective the application of a sustainability assessment to solid biofuels systems. A total of 82 studies were pre-selected with this approach. The main or most unique contributions were then selected and are the eleven studies from Table 1.

The selection in Table 1 represents well the features and focus of most frameworks in the literature that find application to SB systems. After the analysis, the identified research gaps were as follows: (1) sustainability dimensions-frameworks focus on environmental, social, and economic dimensions, and the institutional and technical dimensions are seldom included [7, 12, 14, 15]; (2) indicators-many provide a list of principles, criteria, and possible indicators (some of them including very long lists and ambiguous names), leaving the practitioner the decision of which to include and how to measure, calculate, and interpret these indicators [18-20]. Without a clear definition and calculation procedures for the indicators, it is difficult or even impossible to apply the framework to specific cases with the available information on the method; (3) case studies-many frameworks do not exemplify their application to a case study [7-12]; therefore, they still lack validation on their applicability to specific contexts, or different types and scales of systems; (4) assessment approach-there are three main types of frameworks: those relying on heavy computation, optimization and modeling of system characteristics, and mostly directed to sector-wide analysis [7-9]; those intended for the continuous improvement of a system, which require a measured baseline of the selected indicators and monitoring over time $[9,12-14]$, and those intended only to compare two or more systems. The latter mostly rely on Multi-Criteria Decision Analysis (MCDA) [15-17], which requires definition of objectives and preferences of stakeholders to generate the required criteria and/or indicators. Both approaches require a comparison to make a value judgment on the sustainability of the system, whether against the same system in a previous time state, or against another system or scenario. 


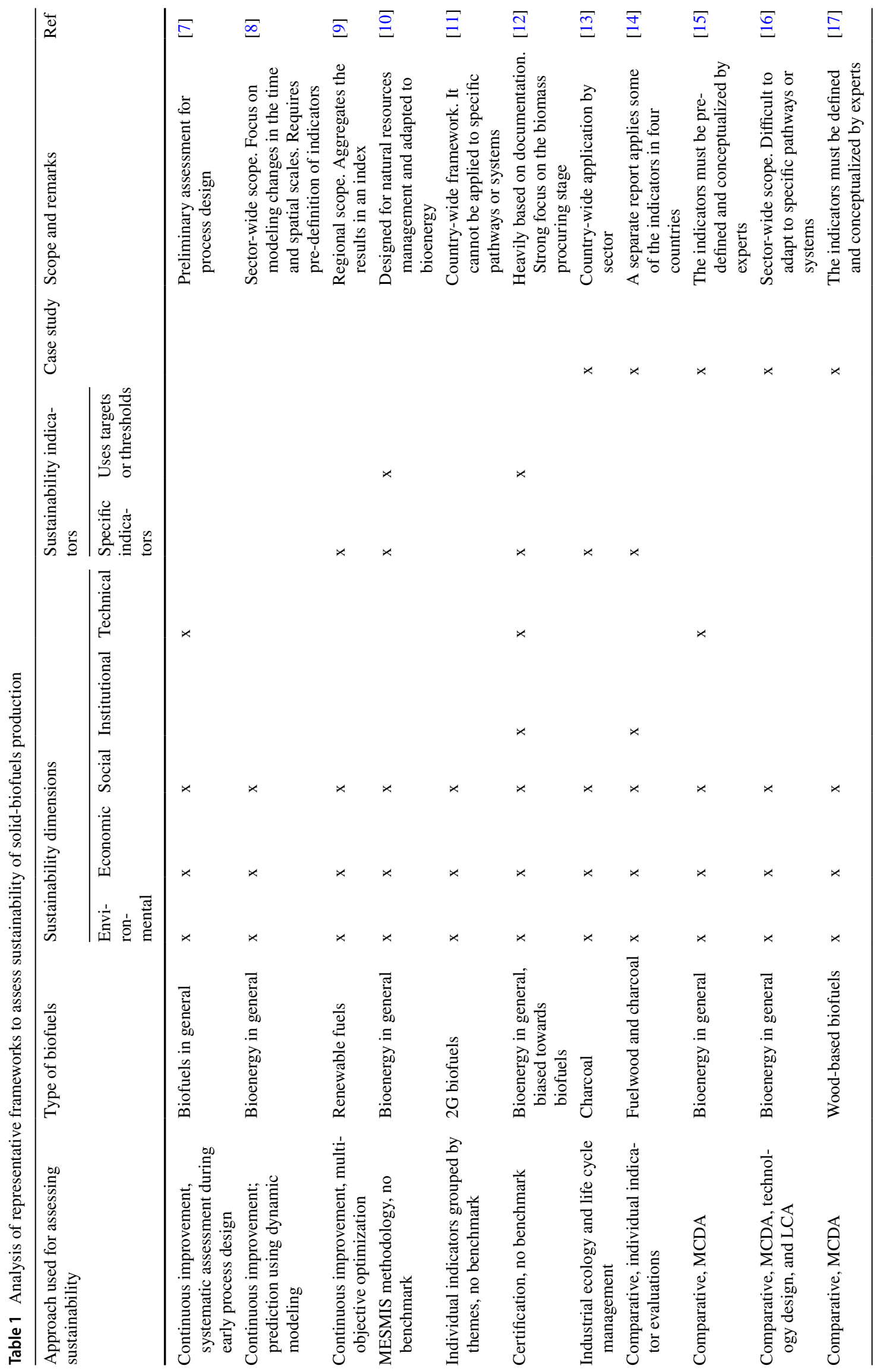




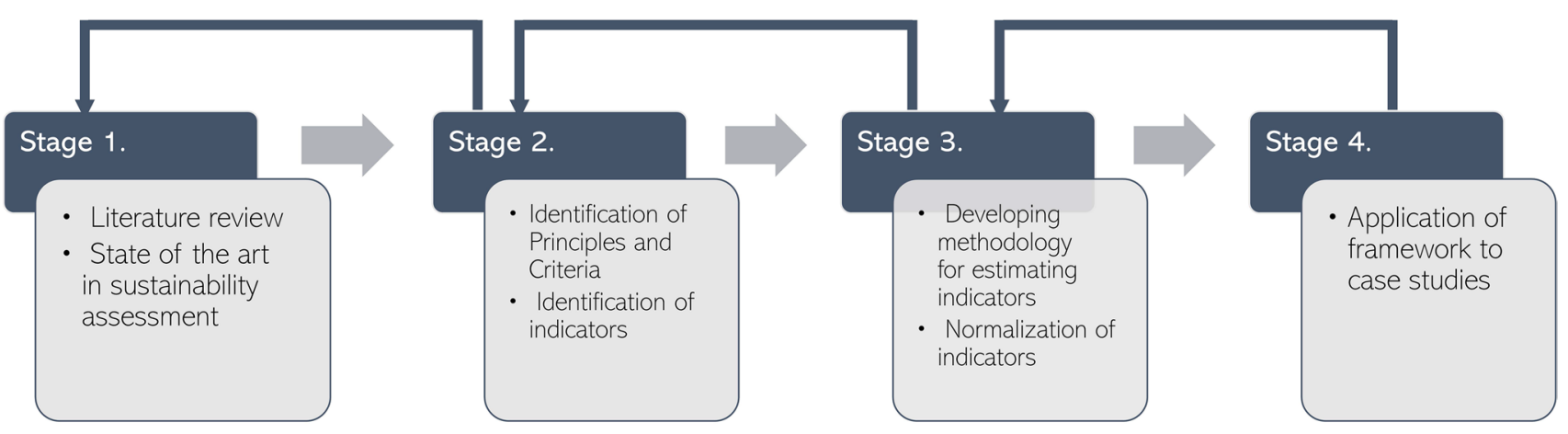

Fig. 1 Development stages of the methodological framework and indicators. Feedback arrows indicate the iterative process between stages informed by field application via case studies

This means that standalone evaluations, using for example distance-to-target indicators, are not available, except on certification schemes and a couple of [10-12]; (5) geographical scope-most frameworks were developed by institutions in developed countries, with a global approach to sustainable bioenergy systems, mostly modern, or including all types of renewable energy. This may be a reason why it is troublesome to apply some frameworks or indicators to traditional or informal SB systems that predominate in the Global South (for example, fuelwood or charcoal production and use for heating and cooking purposes in rural South America); (6) systemic approach-for decision-making, a systemic evaluation is the most appropriate. Existing methods with this scope, however, assume the existence of large historical datasets, easily accessible and at low cost [3, 8], or may require undertaking complex calculations [16]; this poses a problem for many countries in the Global South where data gap challenges are often cited as limiting factors. On the other hand, some frameworks are designed for specific stages of the bioenergy life cycle [21].

After the revision of frameworks previously summarized, it became apparent that any choice of an existing framework would require significant adjustments before being able to accommodate the previously stated project needs. Moreover, it has been cited that in the intrinsic complexity of biofuel production systems, and the multidimensionality of the concept of sustainability, a unified framework is necessary for its evaluation, focused on specific contexts $[7,16]$, in the case of this article, the Mexican context. Hence, the objective of this paper is designing and testing a streamlined methodological framework and its indicators to assess the sustainability of SBs' production in Mexico, with the following features: (a) useful to assess dissimilar biomass sources, pathways, and end-uses in a consistent manner and without the need of benchmarking; (b) provides a streamlined set of indicators that, even if small in number, provides significant information about the system, and that are clearly defined; (c) requires only data that case studies can easily provide, without the need of long time-series data; (d) allows for a multidimensional, transparent discussion of the system (no over-aggregation of information) but simultaneously; (e) portrays results in a simple and straightforward format, understandable to a wide audience.

\section{Methodology}

The framework was developed in an inclusive, iterative, and reflexive process that lasted for approximately 4 years. During this time, a core set of project participants held a series of 10 workshops, meetings, discussions, and fieldwork to develop the framework, occasionally inviting external experts to advise on specific themes, indicators, and approaches. More than 60 unique individuals participated at different stages to develop the framework. Retrospectively, the process can be described as four key stages linked by a series of feedback loops representing the role of fieldwork application to refine indicators and their acquisition methods (Fig. 1). These four stages were as follows: (1) developing the state-of-the-art of sustainability assessment frameworks for bioenergy, (2) defining the principles and criteria required to uphold and propose a first set of indicators, (3) developing a transparent process for the calculation and the normalization of each indicator, (4) applying the framework to six case studies through fieldwork and literature reviews (of which only three are reported in this paper). After this, a final workshop was held to reflect on the direct experiences of each case study. These experiences were collated to identify key issues that facilitate or limit the application of the methodology, and whether these issues were necessarily linked to the methodology, or to the nature of the case study itself (e.g., informal versus formal businesses, industrial versus residential scale, forest- versus agriculture-derived biomass sources). 
Table 2 Principles, criteria, and indicators of the framework

\begin{tabular}{lll}
\hline Principle & Criterion & Indicator ID and name \\
\hline$S B$ should:
\end{tabular}

SBs should:

1. Avoid the degradation of ecosystems

2. Maintain or improve air quality

3. Conserve and protect water resources

4. Promote local development and satisfy local energy needs by:

1.1 Applying best practices across all the system stages that generate or maintain favorable conditions for biodiversity or avoid unfavorable ones

1.2 Reducing anthropogenic greenhouse gases (GHGs) emissions in the life cycle when compared to other options of energy sources for comparable end-uses

2.1 Maintaining emission levels of criteria pollutants below maximum permitted levels and within recommended thresholds to reduce risk of causing respiratory diseases

3.1 Keeping consumptive water-use within or below the current levels applicable to the production of other energy sources of comparable end-uses

3.2 Maintaining water discharges below the maximum permissible levels of major contaminant species

4.1 Being economically viable

4.2 Resulting in positive net energy returns

\subsection{Minimizing negative effects over human} health

4.4 Promoting quality and decent working conditions

5.1 Complying with national and international regulations that may apply to the sector, including labor, environmental, fiscal and other applicable laws

5.2 Promoting institutional responsibility towards employees and local communities
BID: Biodiversity impact diagnosis

GHGm: Mitigation of GHG emissions

PMe: Particulate matter emissions

COe: Carbon monoxide emissions

WINT: Water intensity

WEUT: Contribution to water eutrophication

nBCR: Normalized benefit-cost ratio nEROI: Normalized energy return on investment

nFER: Normalized fossil energy ratio

PMe: Emissions of particulate matter

COe: Emissions of carbon monoxide

EDIR: Direct employment

EGEN: Gender equality among employees

EFORM: Formal employment

EDU: Educational level of workers

EARN: Average earnings per capita

ISD: Institutional sustainability diagnosis

ISD: Institutional sustainability diagnosis comply with applicable laws and fulfil thei munity
In Table 2, there are three criteria that could not be satisfactory addressed with simple indicators: 1.1 , which refers to biodiversity impacts, and 5.1 and 5.2, which refer to the institutional sustainability. It was agreed that proposing numerical indicators would not reflect the minimally desirable information for these criteria, so two diagnostic studies were proposed instead (coded BID and ISD, respectively). The main features of these diagnostic studies are explained later. In addition to structuring the framework based on principles and criteria, care was taken to select a final set of indicators that provides information on all sustainability dimensions and their intersections, as shown in Fig. 2. Care was taken to clearly define the calculation procedure and the scope of all indicators. The scope of all indicators in the context of the system's life cycle is represented in Fig. 3. 
PMe - Particulate matter emissions COe - Carbon monoxide emissions WINT - Water intensity WEUT - Contribution to water eutrophication

EGEN - Gender equality among employees EDU - Educational level of workers

EDIR - Direct employment EARN - Average earnings per capita EFORM - Formal employment

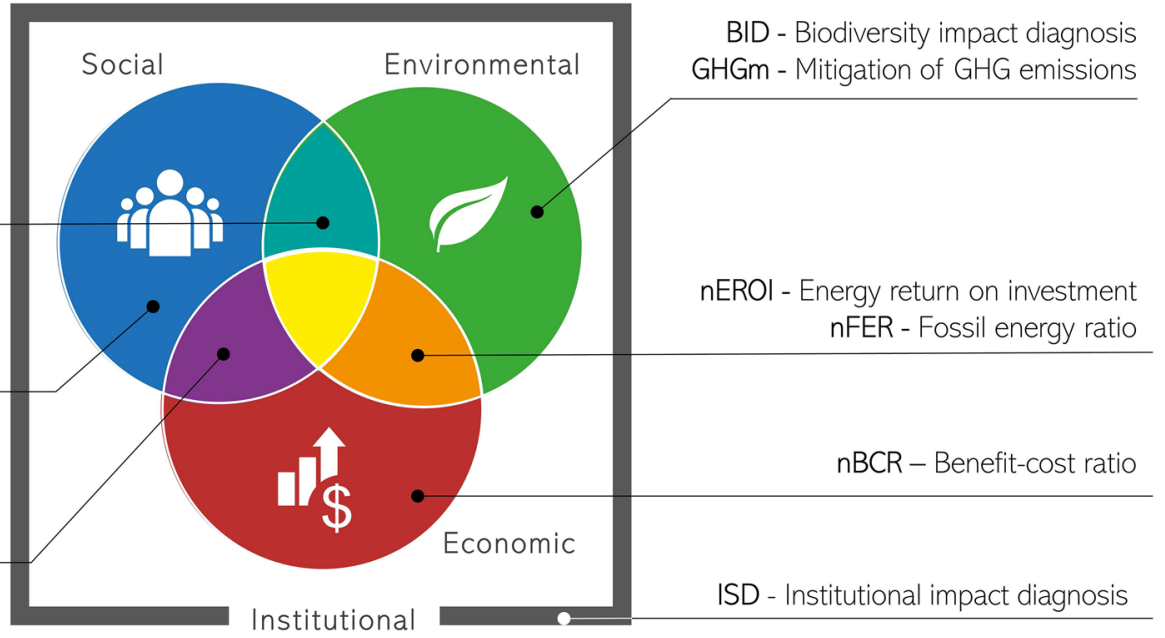

Fig. 2 Distribution of the indicators among the sustainability dimensions and their intersections

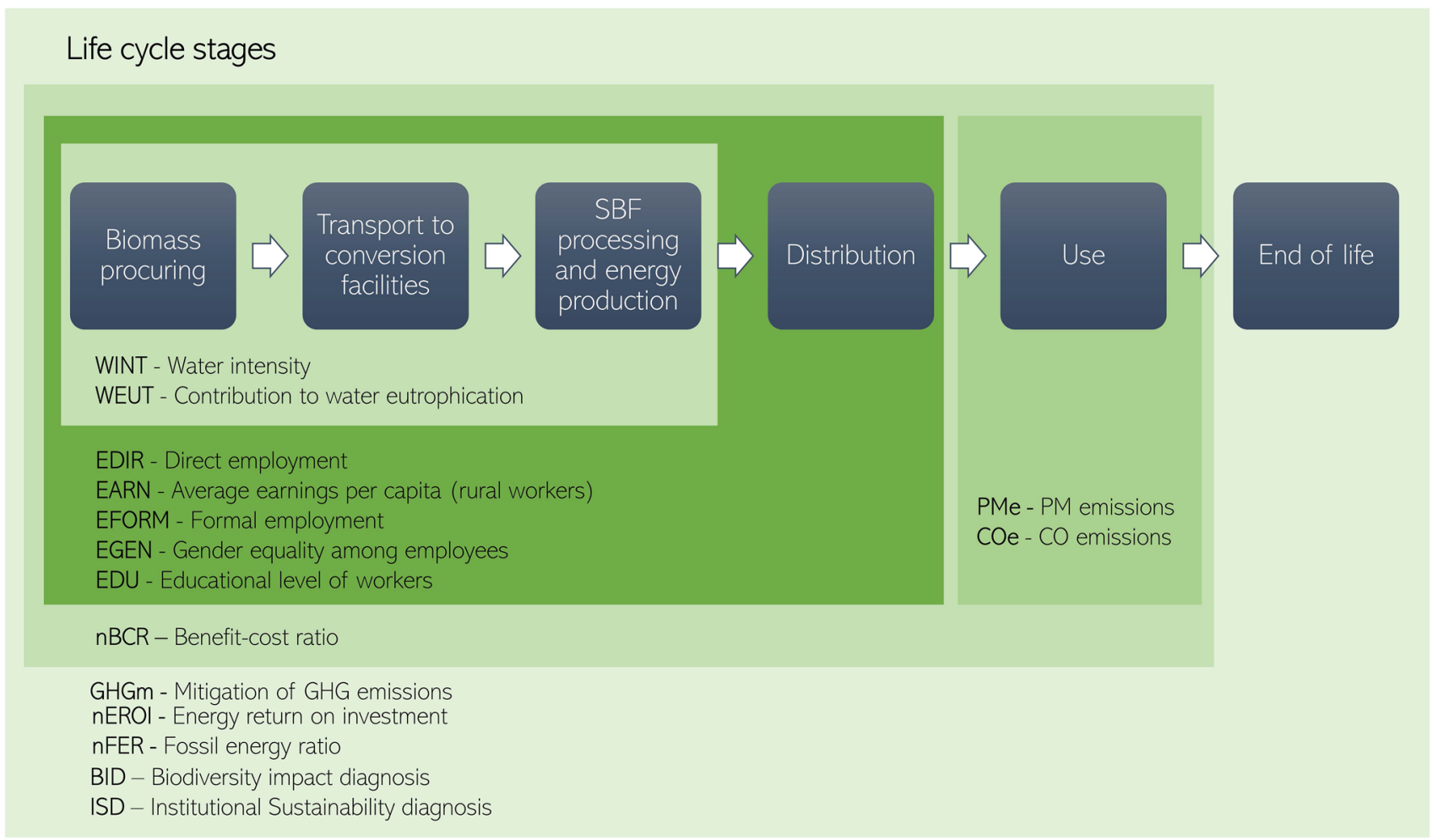

Fig. 3 Life cycle scope of the proposed indicators

The numerical indicators reflect the state of the SB system in a particular sustainability issue. To measure the progress of a system towards sustainability, one may register the change of the indicators' values over time. After normalization, all indicators are expressed in a so-called sustainability scale [24]. This scale was defined to be consistent with the concepts of planetary boundaries [25] and absolute sustainability [26]. In short, the normalized indicators will be zero at their best possible state (ideal value) and will be equal to unity when at their minimum acceptable value, that is, a sustainability threshold or tipping point defined for each indicator. The tipping points were defined on a scientific basis (thermodynamic or physicochemical limits, environmental regulations) and when not applicable, using public 
policy on sustainability targets at the national (national regulations and targets, Nationally Determined Contributions) or international levels (best practices, benchmarking). Hence, normalized indicators with values greater than 1 denote departure from these sustainability targets.

Table 3 summarizes the definitions of the sustainability scale of all indicators. Even though these definitions were devised in the context of Mexico, the framework is flexible enough to incorporate equivalent values, regulations, etc. for other countries or regions where similar data is available. The variables and procedures to calculate the indicators are summarized in Table 4. Then, the next sections describe in detail the indicators.

\section{Mitigation of GHG Emissions}

Mitigation of anthropogenic GHG emissions is highly desirable in the energy sector, responsible of around $72 \%$ of global $\mathrm{CO}_{2 \mathrm{eq}}$ emissions. Bioenergy systems have the potential to produce energy with close to zero or even negative net emissions [23]. Mexico's Nationally Determined Contribution is $50 \%$ mitigation by 2050 , and the contribution of SBs can be significant in displacing fossil fuels in the two sectors with the highest contribution to national GHG emissions, which are oil and gas (12\%) and electricity generation (19\%).

The mitigation of GHG Emissions (GHGm) is estimated by comparing the Global Warming Potential (GWP) of the SB system against that of a reference system (defined as one providing the same functions, using equivalence relations, on a business-as-usual scenario, much as it is usually done in LCA studies). The GWP of both systems is estimated using the GWP100 impact category of the CMLIA method or an equivalent method. The methodological choices for constructing the life cycle inventories were as follows: cradle-to-grave system boundaries but excluding infrastructure-related emissions, energy allocation for flows within the system boundaries, and market-value allocation for biomass inputs; mostly primary data were used (interviews and first-hand information) for direct inputs in the SB system, and ecoinvent v.3.3 APOS modules for both indirect inputs and processes in the SB's life cycle, and for the entire reference system.

\section{Particulate Matter Emissions}

Ambient air pollution is a major environmental health problem, being correlated to prevalence of cardiovascular and respiratory disease, and cancer. Indoor smoke due to cooking and heating with biomass, kerosene, and coal is also a serious health risk involving more than three billion people, mostly from low- to middle-income countries. Specifically, fine particulate matter $\left(\mathrm{PM}_{2.5}\right)$ has been closely associated to cancer incidence, especially lung cancer. In Mexico, fuelwood has around 16 million exclusive users (around 90\% of rural population), and almost 6 million of mixed users (those using fuelwood in tandem with liquefied-petroleum gas, or LPG), which exposes above 22 million people to said risks [30]. Hence, decreasing industrial smokestack emissions and traditional fuelwood use can significantly avert these health risks.

The most meaningful criterion pollutants from the combustion of SB are PM and carbon monoxide (CO) [18]. When the end-use device is located indoors, or its emissions may accumulate in habitable spaces, the World Health Organization's (WHO) indoor air quality guidelines $(10 \mu \mathrm{g}$ $\mathrm{PM}_{2.5} / \mathrm{m}^{3}$ annual mean, or $25 \mu \mathrm{g} \mathrm{PM}_{2.5} / \mathrm{m}^{3}$ 24-h average) may apply. For industrial biomass boilers, smokestack emissions must comply with maximum permissible limits for the sector.

\section{Carbon Monoxide Emissions}

Carbon monoxide's concentration in atmospheric air comes mainly from incomplete combustion of fuels, including SBs. Direct inhalation causes respiratory problems, and $\mathrm{CO}$ in the atmosphere is precursor of global warming and smog formation. Indoor $\mathrm{CO}$ concentrations are also associated to fuelwood burning in rural Mexico. Similarly to PM, the reduction of $\mathrm{CO}$ levels in ambient air may contribute to reduce morbidity associated to cardiovascular, respiratory, and acute and chronic neuropathies, including asthma. Following the same logic for monitoring PM levels from SB combustion, the monitoring conditions and thresholds are defined depending on the end-use devices: for enclosed spaces, the WHO indoor air quality guidelines $\left(7 \mathrm{mg} / \mathrm{m}^{3}\right.$ 24-h average), and for boilers smokestack emissions, the NOM-170-SEMARNAT Mexican regulation $\left(500 \mathrm{ppm}_{V}\right)$.

\section{Water Intensity}

In 2017, Mexico was placed 49th among the countries with the higher water intensity, with an annual consumptive use of $87,840 \mathrm{hm}^{3}$ of water. The national water stress was $19.5 \%$, considered low, but with a great regional variation. Thus, while the lowest stress was in the south (Chiapas state) with $1.7 \%$, the highest value was in the Valle de Mexico with $141.4 \%$ (data from the 2018 Atlas of Water in Mexico, published by the Water National Commission, CONAGUA). The water intensity in oil extraction and processing is a key indicator of water use on energy efficiency. According to the Economic Commission for Latin America and the Caribbean (CEPAL), the consumptive water decreased from 0.022 to $0.018 \mathrm{hm}^{3} / \mathrm{GWh}$, from 2005 to 2016 , due to energy efficiency measures in power plants, decommissioning of inefficient plants, and the introduction of renewable energy. It is expected that the expansion of renewable energies helps 


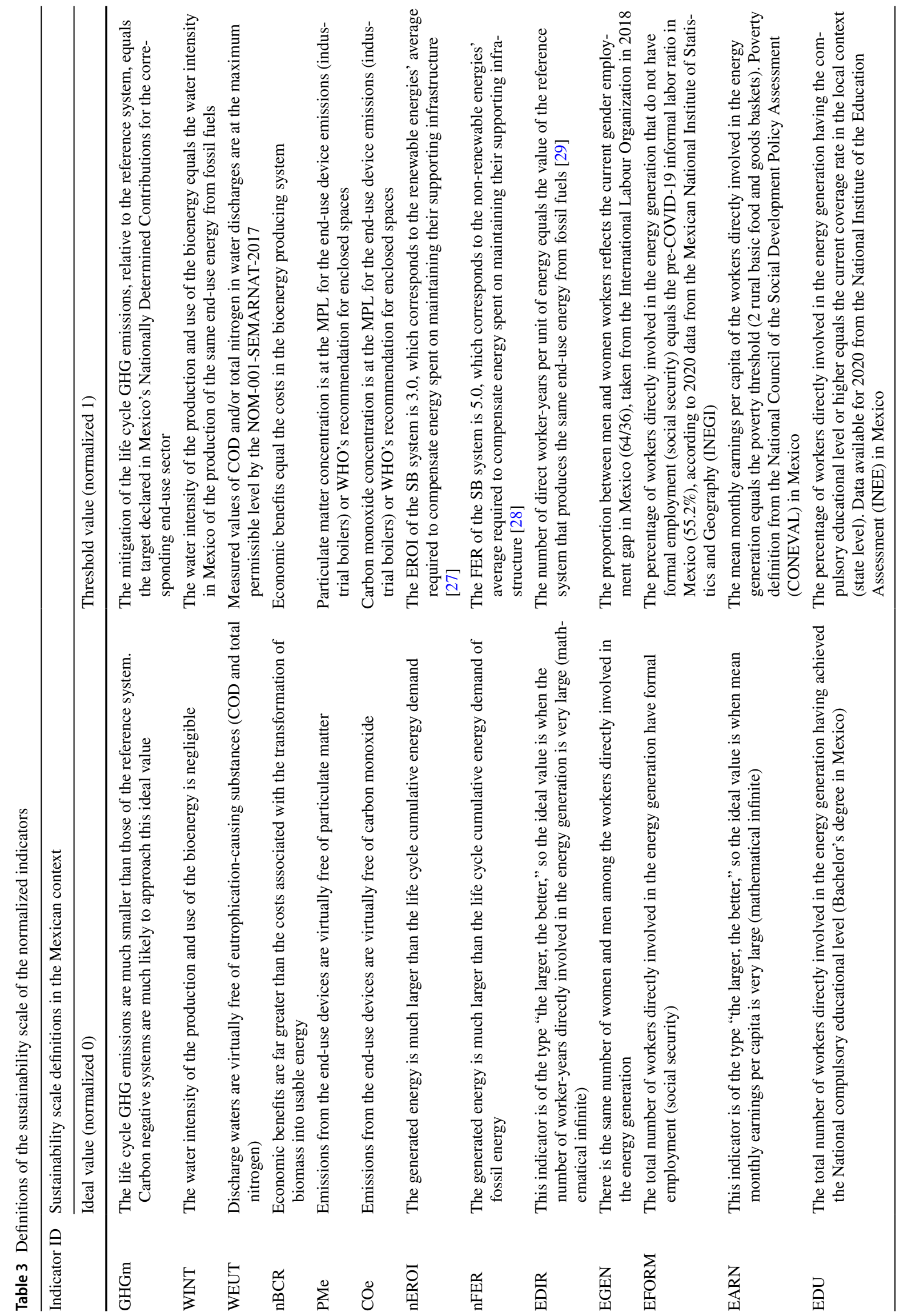


Table 4 Equations used for the calculation and normalization of the indicators

\begin{tabular}{|c|c|c|c|}
\hline Indicator ID and name & Calculation method & $\mathrm{Eq}$ & Variables \\
\hline $\begin{array}{l}\text { GHGm: Mitigation of } \\
\text { GHG emissions }\end{array}$ & $\begin{array}{l}\mathrm{GHGm}=M^{*}=\frac{e^{M_{t}}}{e^{M}} \\
M=\frac{G_{\mathrm{ref}}-G_{b}}{G_{\mathrm{ref}}}\end{array}$ & (1) & $\begin{array}{l}M^{*} \bullet \text {, normalized mitigation of GHG emissions }(-) \\
M_{t} \bullet \text {, threshold of the mitigation of the GHG emissions, } \\
\text { expressed as fraction }(-) \\
M \bullet \bullet \text {, mitigation of GHG emissions by the bioenergy } \\
\text { system, expressed as fraction (-) } \\
G_{\text {ref }} \bullet \text {, life cycle GHG emissions of the reference system } \\
\left(\mathrm{g} \mathrm{CO}_{2 \mathrm{eq}} / \mathrm{MJ}\right) \\
G_{b} \bullet, \text { life cycle GHG emissions of the bioenergy system } \\
\quad\left(\mathrm{g} \mathrm{CO}_{2 \mathrm{eq}} / \mathrm{MJ}\right)\end{array}$ \\
\hline $\begin{array}{l}\text { PMe: Particulate matter } \\
\text { emissions }\end{array}$ & $\mathrm{PMe}=\mathrm{PM}^{*}=\frac{\mathrm{PM}^{\mathrm{PM}_{t}}}{2}$ & (2) & 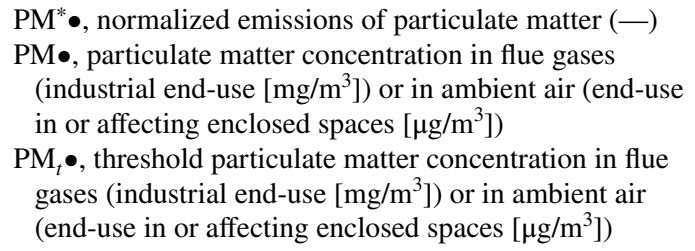 \\
\hline $\begin{array}{l}\text { COe: Carbon monoxide } \\
\text { emissions }\end{array}$ & $\mathrm{COe}=\mathrm{CO}^{*}=\frac{\mathrm{CO}}{\mathrm{CO}_{t}}$ & (3) & $\begin{array}{l}\mathrm{CO}^{*} \bullet \text {, normalized emissions of carbon monoxide }(-) \\
\mathrm{CO} \bullet \text {, carbon monoxide concentration in flue gases } \\
\text { (industrial end-use }\left[\mathrm{ppm}_{\mathrm{V}}\right] \text { ) or in ambient air (end-use } \\
\text { in or affecting enclosed spaces }\left[\mathrm{mg} / \mathrm{m}^{3}\right] \text { ) } \\
\mathrm{CO}_{t} \bullet \text {, threshold carbon monoxide concentration in flue } \\
\text { gases (industrial end-use }\left[\mathrm{ppm}_{\mathrm{V}}\right] \text { ) or in ambient air } \\
\text { (end-use in or affecting enclosed spaces }\left[\mathrm{mg} / \mathrm{m}^{3}\right] \text { ) }\end{array}$ \\
\hline WINT: Water intensity & $\begin{array}{l}\text { WINT }=I_{b}^{*}=\frac{I_{b}}{I_{t}} \\
I_{b}=\frac{w_{b}}{E_{b}}\end{array}$ & (4) & $\begin{array}{l}I_{b}^{* \bullet}, \text { normalized water intensity of the bioenergy system } \\
(-) \\
I_{b} \bullet \text {, water intensity of the bioenergy system }\left(\mathrm{m}^{3} / \mathrm{kWh}\right) \\
I_{t} \bullet \text {, threshold of the water intensity of the reference } \\
\text { end-use energy in Mexico: for electricity generation } \\
\left(=0.011 \mathrm{~m}^{3} / \mathrm{kWh}\right) \text { or for heat generation }\left(0.025 \mathrm{~m}^{3} / \mathrm{GJ}\right) \\
w_{b} \bullet \text { freshwater consumption in the stages of biomass } \\
\text { transformation, energy generation, and end-use }\left(\mathrm{m}^{3} / \mathrm{a}\right) \\
E_{b} \bullet \text {, energy generated in the bioenergy system }(\mathrm{kWh} / \mathrm{a})\end{array}$ \\
\hline $\begin{array}{l}\text { WEUT: Contribution to } \\
\text { water eutrophication }\end{array}$ & 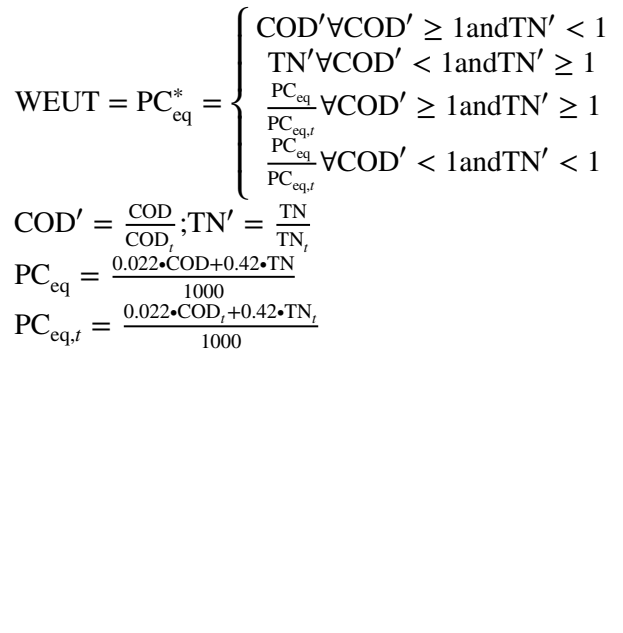 & $(5)$ & 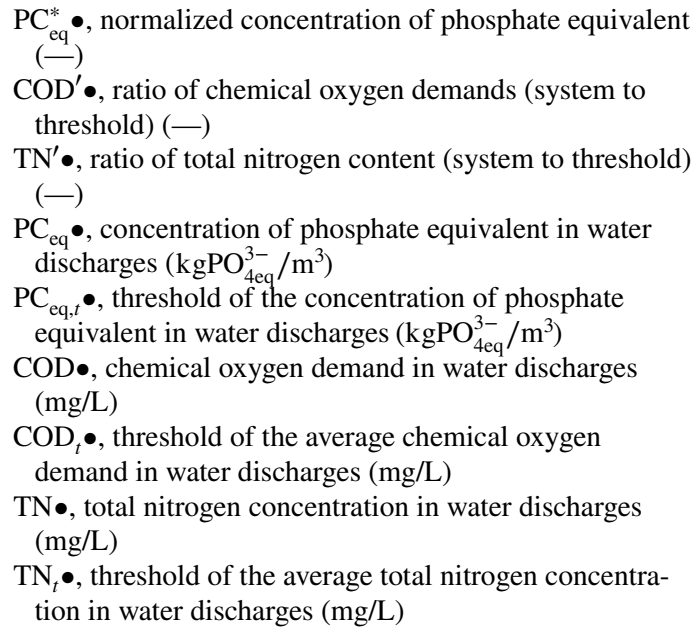 \\
\hline $\begin{array}{l}\text { nBCR: Normalized } \\
\text { benefit-cost ratio }\end{array}$ & $\begin{array}{l}\mathrm{nBCR}=\mathrm{BCR}^{*}=\frac{1}{\mathrm{BCR}} \\
\mathrm{BCR}=\frac{\sum_{i=0}^{T} \frac{B_{i}}{(1+r)^{i}}}{\sum_{i=0}^{T} \frac{C_{t}}{(1+r)^{i}}}\end{array}$ & (6) & $\begin{array}{l}\bullet \mathrm{BCR} * \text {, normalized benefit-cost ratio }(-) \\
\bullet \mathrm{BCR} \text {, benefit-cost ratio }(-) \\
B_{i} \bullet \text {, benefits of the project in the } i \text { th period }(\$) \\
C_{i} \bullet \text {, costs of the project in the } i \text { th period }(\$) \\
\bullet r, \text { real discount rate }(\%) \\
\bullet i \text {, time period of analysis (year) } \\
\bullet T, \text { total number of analyzed periods (years) }\end{array}$ \\
\hline
\end{tabular}


Table 4 (continued)

\begin{tabular}{|c|c|c|c|}
\hline Indicator ID and name & Calculation method & $\mathrm{Eq}$ & Variables \\
\hline $\begin{array}{l}\text { nEROI: Normalized } \\
\text { energy return on invest- } \\
\text { ment }\end{array}$ & $\begin{array}{l}\mathrm{nEROI}=\mathrm{EROI}^{*}=\frac{\mathrm{EROI}_{t}}{\mathrm{EROI}} \\
\mathrm{EROI}=\frac{E_{b}}{E_{d}}\end{array}$ & (7) & $\begin{array}{l}\text { EROI* } \bullet \text {, normalized EROI }(-) \\
\text { EROI }_{\bullet} \bullet \text {, threshold value of the EROI for renewable } \\
\text { energy }(=3.0)[27] \\
\text { EROI } \bullet \text {, Energy return on investment of the bioenergy } \\
\text { system }(-) \\
E_{b} \bullet \text {, energy generated in the bioenergy system (MW) } \\
E_{d} \bullet \text {, life cycle cumulative energy demand of the bioen- } \\
\text { ergy system (MW) }\end{array}$ \\
\hline $\begin{array}{l}\text { nFER: Normalized fossil } \\
\text { energy ratio }\end{array}$ & $\begin{array}{l}\mathrm{nFER}=\mathrm{FER}^{*}=\frac{\mathrm{FER}_{t}}{\mathrm{FER}} \\
\mathrm{FER}=\frac{E_{b}}{E_{d, f}}\end{array}$ & (8) & $\begin{array}{l}\text { FER } \bullet \bullet \text {, normalized FER }(-) \\
\operatorname{FER}_{t} \bullet \text {, threshold value of the FER for renewable energy } \\
(=5.0)[28] \\
\text { FER } \bullet \text {, fossil energy ratio of the bioenergy system (-) } \\
E_{b} \bullet \text {, energy generated by the bioenergy system (MW) } \\
E_{d, f} \bullet \text {, life cycle cumulative fossil-energy demand of the } \\
\text { bioenergy system (MW) }\end{array}$ \\
\hline EDIR: Direct employment & $\begin{array}{l}\mathrm{EDIR}=\mathrm{DE}^{*}=\frac{\mathrm{DE}_{t}}{\mathrm{DE}} \\
\mathrm{DE}=\frac{\mathrm{WT}}{E_{b}^{1}}\end{array}$ & (9) & 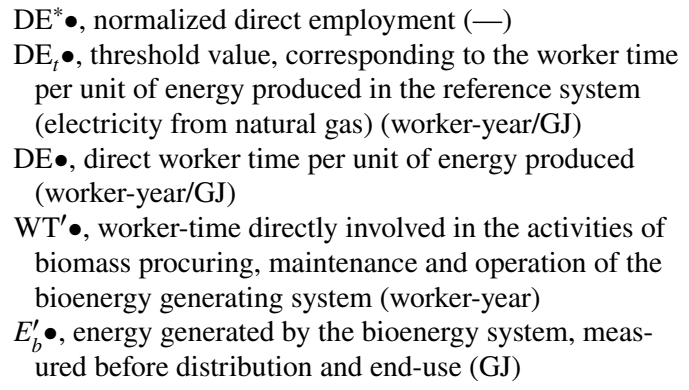 \\
\hline $\begin{array}{l}\text { EGEN: Gender equality } \\
\text { among employees }\end{array}$ & $\begin{array}{l}\mathrm{EGEN}=\mathrm{GE}^{*}=\frac{(50-\mathrm{GE}) \cdot \mathrm{GE}_{t}}{\left(50-\mathrm{GE}_{t}\right) \cdot \mathrm{GE}} \\
\mathrm{GE}=\frac{\min \left(W_{M}, W_{W}\right)}{W_{M}+W_{F}} \times 100\end{array}$ & (10) & 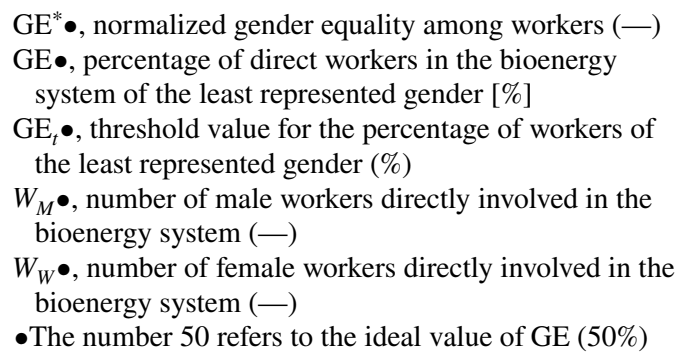 \\
\hline $\begin{array}{l}\text { EFORM: Formal employ- } \\
\text { ment }\end{array}$ & $\mathrm{EFORM}=\mathrm{FE}^{*}=\frac{(100-\mathrm{FE}) \cdot \mathrm{FE}_{t}}{\left(100-\mathrm{FE}_{t}\right) \cdot \mathrm{FE}}$ & (11) & $\begin{array}{l}\mathrm{FE}^{*} \bullet \text {, normalized formal employment }(-) \\
\bullet \mathrm{FE} \text {, percentage of direct workers in the bioenergy sys- } \\
\text { tem having formal employment (social security) }(\%) \\
\mathrm{FE}_{t} \bullet \text {, threshold of the percentage of workers having } \\
\text { formal employment (social security) }(\%) \\
\bullet \text { The number } 100 \text { refers to the ideal value of FE }(100 \%)\end{array}$ \\
\hline $\begin{array}{l}\text { EDU: Educational level } \\
\text { of workers }\end{array}$ & $\mathrm{EDU}=\mathrm{EL}^{*}=\frac{(100-\mathrm{EL}) \cdot \mathrm{EL}_{t}}{\left(100-\mathrm{EL}_{t}\right) \cdot \mathrm{EL}}$ & (12) & 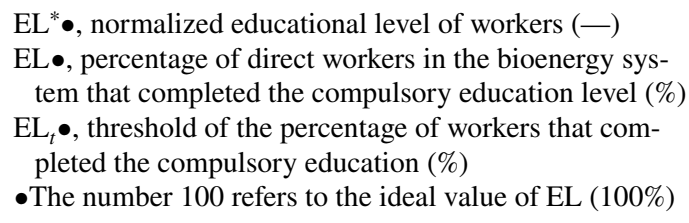 \\
\hline $\begin{array}{l}\text { EARN: Average earnings } \\
\text { per capita }\end{array}$ & $\begin{array}{l}\mathrm{EARN}=\mathrm{AE}^{*}=\frac{\mathrm{AE}_{t}}{\mathrm{AE}^{2}} \\
\mathrm{AE}=\frac{1}{12 \cdot W_{r}} \sum_{i=1}^{W_{r}} \mathrm{AE}_{i}\end{array}$ & (13) & $\begin{array}{l}\mathrm{AE}^{*} \bullet \text {, normalized average earnings per capita }(-) \\
\mathrm{AE} \bullet \text {, average earnings per capita of the direct rural } \\
\text { workers in the biorefinery system (\$/month/worker) } \\
\mathrm{AE}_{t} \bullet \text {, poverty threshold defined for the rural population } \\
\text { in Mexico (\$/month/worker) } \\
W_{r} \bullet \text {, number of direct rural workers directly involved in } \\
\text { the bioenergy system }(-) \\
\mathrm{AE}_{i} \bullet \text {, average annual earnings of the } i \text { th worker }(\$ / \mathrm{a})\end{array}$ \\
\hline
\end{tabular}


to further reduce the water intensity of energy generation. Mexico has a national target of a $35 \%$ renewable electricity share by 2024 . Should this target be achieved, the water intensity of the electricity generation would reach $0.011 \mathrm{~m}^{3} /$ $\mathrm{kWh}$ (projection calculated from the latest water intensity data in the sector), which may be used as a threshold value for this indicator. In the case of heat generation, the latest estimated value of water intensity for the natural gas extraction and processing may be used instead $\left(0.025 \mathrm{~m}^{3} /\right.$ GJ). To preserve consistency with these threshold values, in the calculation of this indicator, only consumptive water in the stages of biomass procuring and SB generation or the electricity generation should be included (see Fig. 3). The energy produced is quantified at the production end (at the factory gate).

\section{Contribution to Water Eutrophication}

This indicator estimates the eutrophication potential of water bodies from the macronutrient contents in wastewater of the SB system and compares it with maximum permissible levels (MPLs) from national regulations. Eutrophication of water bodies refers to the excessive content of organic matter and/or nutrients in water bodies which, in the long term, sharply increase the presence of aquatic plants and algae, while decreasing the oxygen dissolved in water, as well as its biodiversity. Also, high nitrate concentrations (above $0.2 \mathrm{mg} / \mathrm{L}$ ) in drinking water are known to promote methemoglobinemia in children (decreasing the blood's capacity of oxygen transport). In Mexico, at least 35\% of the monitored surface water bodies showed high concentration of phosphates, and $27 \%$ showed high concentration of nitrates.

The chemical oxygen demand (COD) and total nitrogen (TN) content in industrial and agro-industrial wastewaters are high contributors to eutrophication of water bodies; thus, these two parameters were aggregated in this indicator. The threshold values were fixed at the MPL concentrations of these two components in the national regulation for wastewater discharges and then aggregated to a single value for normalization. The aggregation procedure, Eq. (5), ensures that if at least one of the concentration values (TN or COD) is above the MPL, the normalized indicator will be greater than one (in the unsustainable region).

Normalized Benefit-Cost Ratio The benefit-cost ratio (BCR) of a project is the ratio between the benefits and the costs expressed in present value (PV). Benefits and costs are both calculated at a discount rate $r$, and over an analysis period $T$ equal to the project's useful life. If the BCR is greater than unity, the project is economically feasible; also, the greater the ratio, the more profitable the project will be. The main steps to calculate this indicator are as follows: (1) all investment, energy, operation, and maintenance costs are identified and valued in the same constant currency throughout the analysis period; (2) all benefits (income, savings, and avoided costs) are identified and valued in the same constant currency (2017 USD in this article); (3) the costs cash flow (represented by negative signs) and benefits cash flow (represented by positive signs) are constructed in PV; (4) the BCR is calculated by dividing the PV of the benefits by the PV of the costs, Eq. (6); and (5) the normalized BCR (nBCR) is merely the reciprocal of BCR, which complies with the sustainability scale (ideal value at 0 , undesirable values above 1 ).

Normalized Energy Return on Investment Energy independence is one of the drivers of renewable energy, internationally [23]. Hence, a part of the success of a bioenergy system is that it generates more energy than that invested in all the operations required for its extraction, transformation, and use [27]. In this study, the energy return on investment (EROI) is the ratio between the energy generated by the SB production system and the energy supplied to the production process during the life cycle, including the energy associated to the production of energy and material inputs [27, 31]. It has been suggested [27] that renewable energy needs an EROI of 3.0 to start providing net energy production (compensating the energy required to maintain supporting infrastructure). In absence of a similar value for SB systems, this value was taken as a threshold.

Normalized Fossil Energy Ratio The fossil energy ratio (FER) is similar to the EROI, but the denominator is replaced by the energy demand corresponding only to non-renewable sources. It is a useful measure to report the potential displacement of fossil energy and commonly used to support the development of bioenergy systems [27, 28, 31]. Similarly to normalized energy return on investment (nEROI), a proxy value for renewable energy of $\mathrm{FER}=5.0$ [28] was taken as the threshold.

Direct Employment Employment opportunities in rural areas is one of the main promises of bioenergy [32]; it represents an incentive to hinder migration and reactivate local economies, contributing to local development [33, 34]. This indicator reports the total number of direct workers (employees, self-employed, or informal workers with a direct benefit from the SB system) involved in the production chain of the bioenergy, from biomass procuring to the bioenergy final use. Jobs associated with the production of indirect life cycle inputs and energy are not included in this indicator. Unfortunately, there are still no benchmark data on this indicator for bioenergy. The most consistent dataset on direct employment for energy generation is on electricity from natural gas in the USA [29], and thus, this value was taken as a proxy threshold for energy production from SBs 
(0.10343003 worker-year/GWh). When counting workeryears in the bioenergy system, 40-h per week is considered equivalent to a full-time job. The quality of the employment is not captured in this indicator, but may be discussed from the simultaneous interpretation with other indicators in this framework (e.g., EGEN, EFORM, EDU, and EARN).

Gender Equality Among Employees Gender equality addresses an important dimension of social sustainability, related to achieving equal opportunities between men and women. Gender equality is a human right with an entire sustainability development goal dedicated to it (SDG 5 "achieving gender equality and empowering all women and girls") and, under Article 4 of the Mexican constitution, men and women are considered equal under the law and promoting gender equality; particularly in the workplace, it is portrayed as a national ambition.

The indicator provides information on the gap of workers of different sex employed as a proportion of direct jobs generated in the system attributable to bioenergy production, including self-employment. Jobs associated with the production of indirect life cycle inputs and energy are not included in this indicator. The ideal level for the indicator is a zero gap, or $50 \%$ (i.e., equal number of men and women are employed). Given local and national demographic distributions, however, this is not always feasible. Consequently, a threshold of $35.7 \%$ was selected, based on the current gender employment gap in Mexico, reported by the International Labour Organization in 2018. This gap is defined as the maximum acceptable value in the bioenergy system. Note that this indicator does not provide information about the type or quality of the jobs held by women relative to men.

Formal Employment Formal employment is defined as having an established working agreement that includes salary or wages, health benefits, and defined work hours and workdays as stipulated by Federal and other laws. Formal employment can provide stability and other financial and social securities that contribute to overall well-being andto some extent-job satisfaction, both of which are key components of social sustainability [35]. Additionally, there is growing public expectations that industry and business will act ethically by formalizing their structures in order to contribute to the common goals of sustainable development [36].

This indicator provides information on the proportion of the labor force that is directly and formally employed in the SB system. Jobs associated with the production of indirect life cycle inputs and energy are not included in this indicator. Ideally, this value should be $100 \%$. However, the threshold value was set at $43.8 \%$ which reflects the 2019 national average labor informality rate for Mexico as published in the National Occupation and Employment Survey.
The universe of workers for this accounting is defined in the direct employment (EDIR) indicator.

Educational Level of Workers The perception of some stakeholders about the jobs created by bioenergy industries is that they are low-quality jobs [37]. In fact, bioenergy has the potential to employ a large and diverse workforce along its value chain, requiring highly variable skill sets and educational levels. In Mexico, where unemployment rates are close to $4 \%$, but with high informality (55\%), it is important that new jobs not only focus on the highly educated and highly skilled, but also generate employment for those with lower education levels. Thus, a balance between highly skilled and less-skilled labor can be deemed favorable for the SB sector.

This indicator considers the level of education of people who work in the SB system, a key dimension for social sustainability [3, 32, 38, 39]. In Mexico, compulsory education is defined up to upper secondary education. This indicator provides information about the share of workers having at least the compulsory educational level. It does not reflect any additional training they may have received (e.g., on-the-job training) to enhance their skills set, even if a formal certificate was emitted. Nonetheless, it provides a useful indication of the educational level needed to engage in the industry. The threshold is defined as the expected share of people with completed compulsory education in the locality, from official national statistics. The universe of workers for this accounting is defined in the EDIR indicator.

Average Earnings Per Capita Bioenergy systems stand out among the renewable energies due to their potential for promoting employment in rural areas [32]. In alignment with SDG 8, decent work, and economic growth, this indicator pretends to monitor effectiveness towards the target of achieving "decent work for all." However, the average income of a rural family unit is more complex than just salaries from jobs or a single activity. The share of the household income from a person's involvement in a bioenergy system is highly variable among systems [40]. Hence, a simpler indication of the economic benefit of a rural worker is the average earnings, either from salaries, wages, or savings. Comparing these earnings to the poverty threshold in rural areas gives an idea of how decent the economic remuneration is. In Mexico, the most stringent poverty threshold is published by the National Council for the Evaluation of Social Development Policies (CONEVAL), defined in 2020 as twice the price of the food and goods basket in rural areas, which in turn was estimated in MX\$2,089.93 (2017 US\$92.13) per month per capita.

Biodiversity Impact Diagnosis Understanding the impact on biodiversity of bioenergy systems is imperative, yet it is 
rarely undertaken and no standardized methods exist [41]. To ensure that the biodiversity impact recognizes impact beyond that of biomass removal, a broad definition of biodiversity was applied that considers "the variability among living organisms from all sources including, inter alia, terrestrial, marine, and other aquatic ecosystems and the ecological complexes of which they are part; this includes diversity within species, between species and of ecosystems" [42]. This definition requires SB developers to think beyond individual species (usually biased towards fauna) and to consider the impacts on various components of habitat including aquatic and edaphic dimensions. Given the richness and complexity of biodiversity, it was considered inappropriate and meaningless to propose a single indicator of biodiversity impact. Moreover, biodiversity assessments can be costly and time-intensive undertakings. Thus, a diagnosis approach was developed that assesses the potential impact of a given SB on 26 taxa located in four main ecosystem complexes: soils, aquatic systems (freshwater), terrestrial vegetation, and terrestrial fauna.

The diagnosis consists primarily of a desktop study that assesses potential impact based on whether (or not) good practices for minimizing negative impact on biodiversity are implemented in the system. Best practices in the industry were identified from industry standards and certification schemes, such as Mexico's standards for sustainable forest management, and agriculture methods. Seven impact levels were assigned, four to indicate favorable impact on biodiversity, including extremely favorable impact if practices went beyond what was required by the standards, and three to indicate negative impact (low harm, medium harm, and very harmful). The level of harm was assigned by conducting a rapid review of mostly scholarly literature reporting on studies that assessed the impact of specific human activity on components of biodiversity. In the absence of studies reporting how biodiversity responds (positively or negatively or neutral) and level of impact (low, medium, high), a value of "unknown" impact was allocated. "Unknown" impact was also assigned in cases where it was not known whether a certain best practice was implemented or not in the system.

The results of the diagnosis are presented as a spreadsheet table with traffic light shading of cells to indicate the level of impact on each taxon for each best practice that could be undertaken at each stage of the system. Pivot charts can be developed to summarize the diagnosis from multiple angles to answer the following questions: Which practice is the least favorable for biodiversity? Which taxa are the most impacted? Which stage of the life cycle is the most impactful? Impacts on marine systems were excluded by choice. However, by applying a similar logic, the diagnosis could be adapted to include impact on coastal systems such as effects of mangroves, estuaries, and marine life. In the interest of space, we do not present in this paper the results of the biodiversity impact diagnosis, which in turn will be reported in a separate article (in preparation).

Institutional Sustainability Diagnosis Institutional sustainability requires assessing "the activities of a particular institution related to the facilitation of decision-making and implementation of sustainability policies" [43], in this case, in the SB sector. As with the biodiversity impact, it was deemed much more meaningful to conduct a comprehensive diagnosis informed by several indicators rather than presenting a single index of institutional sustainability. Thus, an institutional sustainability diagnostic tool was created, applying elements of the Institutional Analysis and Development, which provides a useful structure and checklist of specific system components and their interactions.

The diagnosis focuses on three levels, i.e., legal (fulfillment of legal obligations of an entity towards the state), organizational (fulfillment of an entity's own internal rules and obligations to employees), and contextual (fulfillment of local rules and expectations and its direct and indirect local impact), for which a total of eight categories are assessed (Table 5). A five-step process consisting of (1) identification of policies, laws, and regulations applicable to the SB's value chain; (2) identification of the institutions and/or organizations that regulate the value/ supply chain processes; (3) identification of relevant actors in the value chain, including their specific attributes such as their position, role in decision-making, contribution to information flows, jurisdiction, and level of incidence in the delimitation of norms; (4) documentation and description of the formal and informal rules that affect decisionmaking and the information and transparency in such processes; and (5) assessing issues of property rights, as well as to the formal and informal mechanisms that regulate access to the resources at stake in the value chain.

For each case study, a combination of surveys, semistructured interviews, field observations, and review of publicly available secondary data were used to diagnose the degree to which institutions facilitate, promote, or monitor concrete actions in sustainability. Responses to these questions are converted to an ordinal measurement level with five options $(0,0.25,0.50,0.75$, and 1.00) representing the degree to which the response corresponds to the most desirable situation (1.00) for that variable. These values are represented in a radial graph to visually assess the overall and specific sustainability of an institutional level. In the interest of space, we do not present in this paper the results of the institutional sustainability diagnosis for the case studies, which in turn will be reported in a separate article (in preparation). 
Table 5 Framework for diagnosing institutional sustainability of solid biofuels

\begin{tabular}{|c|c|c|c|c|}
\hline Institutional level assessed & Scope of the analysis & & Category & Evaluation criteria \\
\hline \multirow[t]{2}{*}{$\begin{array}{l}\text { LEGAL_legislative and regula- } \\
\text { tory fulfillment }\end{array}$} & $\begin{array}{l}\text { Legal framework determined by } \\
\text { national and international laws } \\
\text { and regulations }\end{array}$ & 1 & Compliance and surveillance & $\begin{array}{l}\text { Compliance with legal regulations } \\
\text { (environmental, labor, produc- } \\
\text { tive, commercial, access to natural } \\
\text { resources, and land) }\end{array}$ \\
\hline & $\begin{array}{l}\text { Governmental regulatory organiza- } \\
\text { tions }\end{array}$ & 2 & Participation and efficiency & $\begin{array}{l}\text { The nature of relations with regula- } \\
\text { tory bodies and agencies }\end{array}$ \\
\hline \multirow[t]{4}{*}{$\begin{array}{l}\text { ORGANIZATIONAL-fulfillment } \\
\text { of internal rules and expectations }\end{array}$} & Internal rules & 3 & Self-regulation & $\begin{array}{l}\text { Existence and fulfillment of stand- } \\
\text { ards and internal operating rules }\end{array}$ \\
\hline & Internal management & 4 & Transparency & $\begin{array}{l}\text { Transparent organizational } \\
\text { structures for management and } \\
\text { administration }\end{array}$ \\
\hline & Participation in decision-making & 5 & Representativeness & $\begin{array}{l}\text { Opportunities to participate in } \\
\text { organization and in decision- } \\
\text { making }\end{array}$ \\
\hline & Power structures & 6 & Distribution of power & $\begin{array}{l}\text { Ability and opportunities in decision } \\
\text { making and access to resources }\end{array}$ \\
\hline \multirow[t]{2}{*}{$\begin{array}{l}\text { CONTEXT-responsiveness to } \\
\text { impact on local communities }\end{array}$} & Local context & 7 & Social stability & $\begin{array}{l}\text { Types of actions/interventions/ } \\
\text { relations with the local context } \\
\text { and respect of local traditions and } \\
\text { customs }\end{array}$ \\
\hline & $\begin{array}{l}\text { Information sharing and consensus } \\
\text { building }\end{array}$ & 8 & Informality/Illegality & $\begin{array}{l}\text { Costs and benefits to local commu- } \\
\text { nities are commensurate with local } \\
\text { impact }\end{array}$ \\
\hline
\end{tabular}

\section{Case Studies}

The framework was applied to six case studies, selected due to their relevance on the solid-biofuel scene in Mexico. Three of these were selected to illustrate in this article how this framework can describe dissimilar systems which, despite being based on SB, may have very different objectives, scopes, and features, down from the definition of the system's boundaries, up to the end-use of the energy. The calculation of some indicators uses sensitive data that was required to be confidential. Hence, to keep the anonymity of the key informants, the location of the data sources has been omitted. Table 6 and the following text describe the selected case studies.

\section{Case Study "Fuelwood": Fuelwood-Based Heat Generation Using Patsari Cookstoves in Rural Households}

Currently, in Mexico, 23 million people use fuelwood for cooking and boiling water in households. The major use of fuelwood is in U-type open fires. The use of fuelwood in the rural sector has been maintained for hundreds of years and projections show little variation for the next years [30]. Wood collection may also have environmental impacts in the absence of a sustainable forest management is lacking. Also, fuelwood burning in households has negative effects on health, derived from combustion emissions, mainly PM and CO. Despite this, a cultural preference for fuelwood has not allowed replacement by other types of fuels. Hence, one alternative to these problems is the promotion and use of efficient biomass cookstoves, which have a higher thermal efficiency than the open fire and significantly reduce the concentration of unsafe emissions inside kitchens, by directing the fumes outside of and away from enclosed spaces.

The fuelwood system was evaluated in the rural community of El Ajuno, Michoacan. The wood supply comes from two areas: the indigenous communal Reserve (559.7 ha) and an Ejido ${ }^{1}$ Reserve (613.9 ha); both areas are temperate forest with mix of oak (Quercus sp.), pine (Pinus sp.), and other species. In this case study, a 2-year operational period was considered (2018-2020). The forest management areas in El Ajuno have general regulations of access and use of the forest biomass resource, which are overseen and executed by the Ejido assembly and the comuneros; inhabitants have access to fuelwood only in certain areas and in controlled quantities. In the two studied areas, the collection of fuelwood for self-consumption is manual and people occasionally use load animals for transporting the biomass between 1 and $3 \mathrm{~km}$, from the collection area to their homes. The end-use technology in this analysis was the Patsari improved cookstove, since it

\footnotetext{
$\overline{1}$ The Ejido is a Mexican unique land tenancy system in which a piece of land is farmed communally under a system supported by the state.
} 


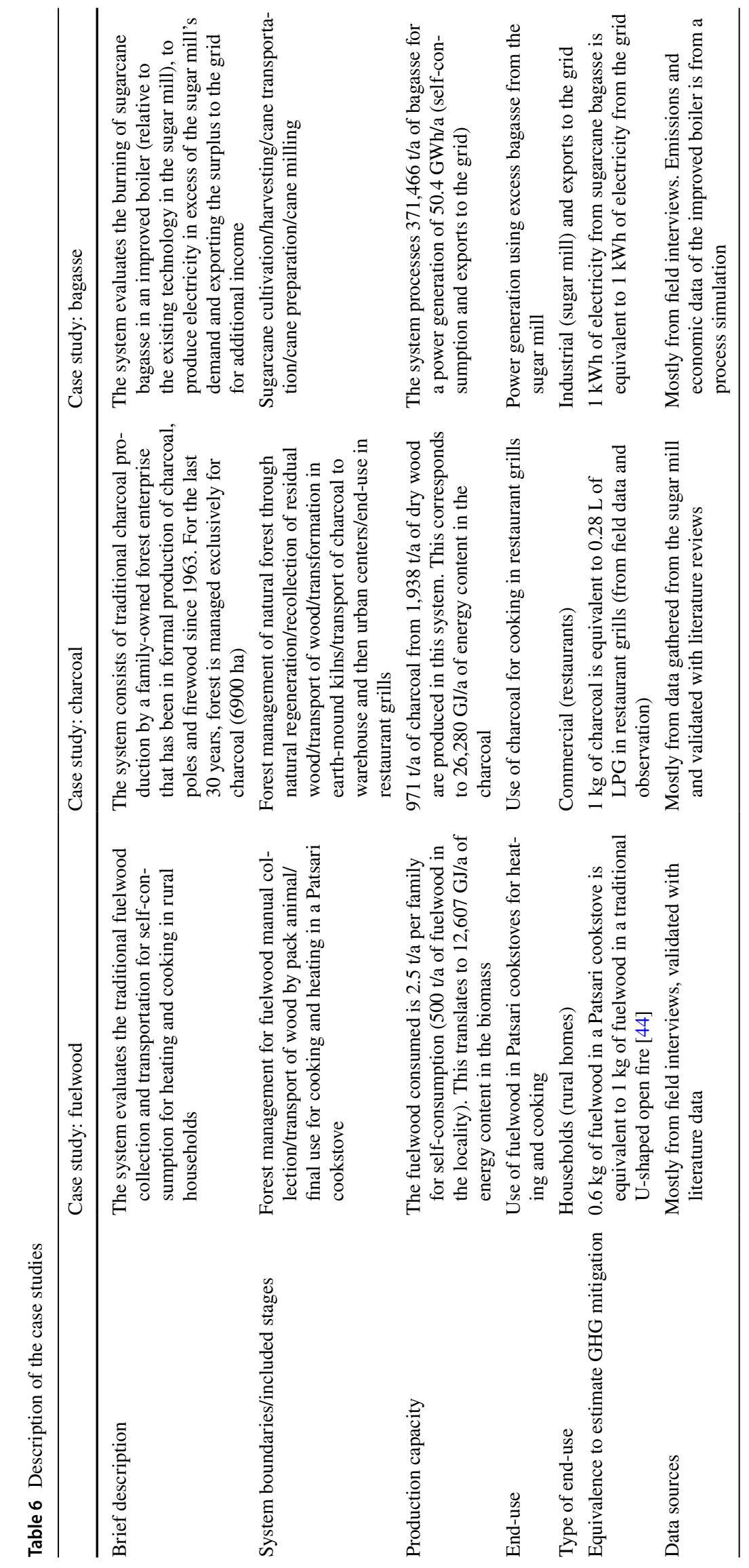


has had a wide penetration in rural communities of Michoacan since 2003 [45]. For this reason, this is the technology considered to have the best opportunity to displace the traditional use of firewood in U-shaped open fires in the region.

\section{Case Study "Charcoal": Charcoal-Based Heat for Grilling in Restaurants}

A strong culture and preference for grilled food in Mexican cuisine means that charcoal is a critical form of bioenergy used in restaurants for food preparation. Despite the existence of relatively affordable subsidized LPG, charcoal consumption has been steadily increasing over the past four decades, in line with a growing middle and upper middle class that regularly visits restaurants. Most charcoal, however, is produced and traded in the informal sector, raising concern about its sustainability.

The case study consists of a family-run forest enterprise that has been in formal operation for more than 50 years with the last 30 years dedicated exclusively to charcoal production. The 6,900 ha of predominantly oak woodlands are managed through 30 -year rotations comprising three 10-year cutting cycles in accordance to a government-approved forest management plan (FMP). The FMP identifies productive, restoration, and conservation zones. Productive zones are further subdivided into forest management units, in which selective and group harvesting of trees is practiced with guidance from a forest technician. Wood is harvested and converted to charcoal by hired labor using traditional earth-mound kilns built with logs and insulated with loosely packed earth and leaves. The single-use kilns are designed to be quick to build, sourcing materials that are directly available in the forest. The average annual production is $971 \mathrm{t}$ of charcoal produced from $30 \%$ of the available productive forest (personal communication). Depending on the accessibility of the terrain, mules are used to transport the charcoal from the kiln site to a road from where it is transported to a warehouse by truck. The enterprise delivers its charcoal directly to consumers in urban areas, covering distances ranging from 35 to $118 \mathrm{~km}$. Restaurant kitchens buying the charcoal use it primarily for grilling, employing locally designed and manufactured commercial grills (stainless steel charcoal grill). Ash and waste produced from these grills are incorporated with all other food and kitchen waste generated in the restaurant and end up in municipal waste facilities. The reference system (displaced use) considered for the GHGm indicator was the use of commercial LPG grills (Tor-crokx model), also commonly used in restaurants. This was deemed to be the most likely alternative to replace or substitute charcoal grills.
Case Study "Sugarcane": Electricity Generation Using Sugarcane Bagasse in Efficient Boilers in a Sugar Mill

Sugarcane bagasse is the second most used solid biofuel in Mexico, with a contribution of $122 \mathrm{PJ}$ of primary energy in 2018, according to national statistics. Sugar mills use the bagasse from the sugar cane milling to meet their heat and electricity needs using cogeneration. A potential for more efficient use of bagasse has been identified, which would allow for exporting remanent electricity to the grid, after covering internal energy demands [46]. This case study analyzes a scenario of efficient cogeneration implementation in a sugar mill in Veracruz, Mexico. Currently, the sugar mill reports an inefficient use of bagasse where it is also necessary to import a small quantity of electricity and fuel oil to satisfy its energy needs.

The studied scenario was then defined as a transformation of the steam generators to more efficient operation conditions, to increase the electricity generation and have a power surplus uploaded to the grid. Data of the improved scenario were taken from process simulation (unpublished results) using the software Aspen Plus 9.2, developed to match the current technical data from the sugar mill as a baseline. The scenario considers the generation of $50.4 \mathrm{GWh} / \mathrm{a}$ (compared to the current generation of the sugar mill of $21 \mathrm{GWh} / \mathrm{a}$ ) for self-supply and exports to the grid, corresponding to a more efficient use of the energy contained in the sugarcane bagasse but preserving all other operation conditions in the sugar mill. The reference system (displaced use) for the calculation of GHGm was electricity from the national grid, which is in fact the energy source displaced by the uploaded electricity.

\section{Results and Discussions}

This methodological framework was developed to meet specific criteria for assessing the sustainability of SBs in countries such as Mexico, namely, that the methodology (1) can be applied to different types of SBs and pathways, (2) provides a streamlined set of indicators that inform on key sustainability issues of SB systems, (3) makes use of indicators that do not rely on excessive amounts of data that is difficult to access, and (4) provides a multidimensional analysis of sustainability that is accessible to a diverse user base. Consequently, the following questions were selected to steer the discussion on the framework's success: Is the framework able to capture sustainability issues of SB systems in all four dimensions with reasonable detail? Can various types of SB be described with minimum modifications of the framework? What types of SB systems are most suitable for the methodology? Does it allow for comparisons among different systems? What are the challenges associated 


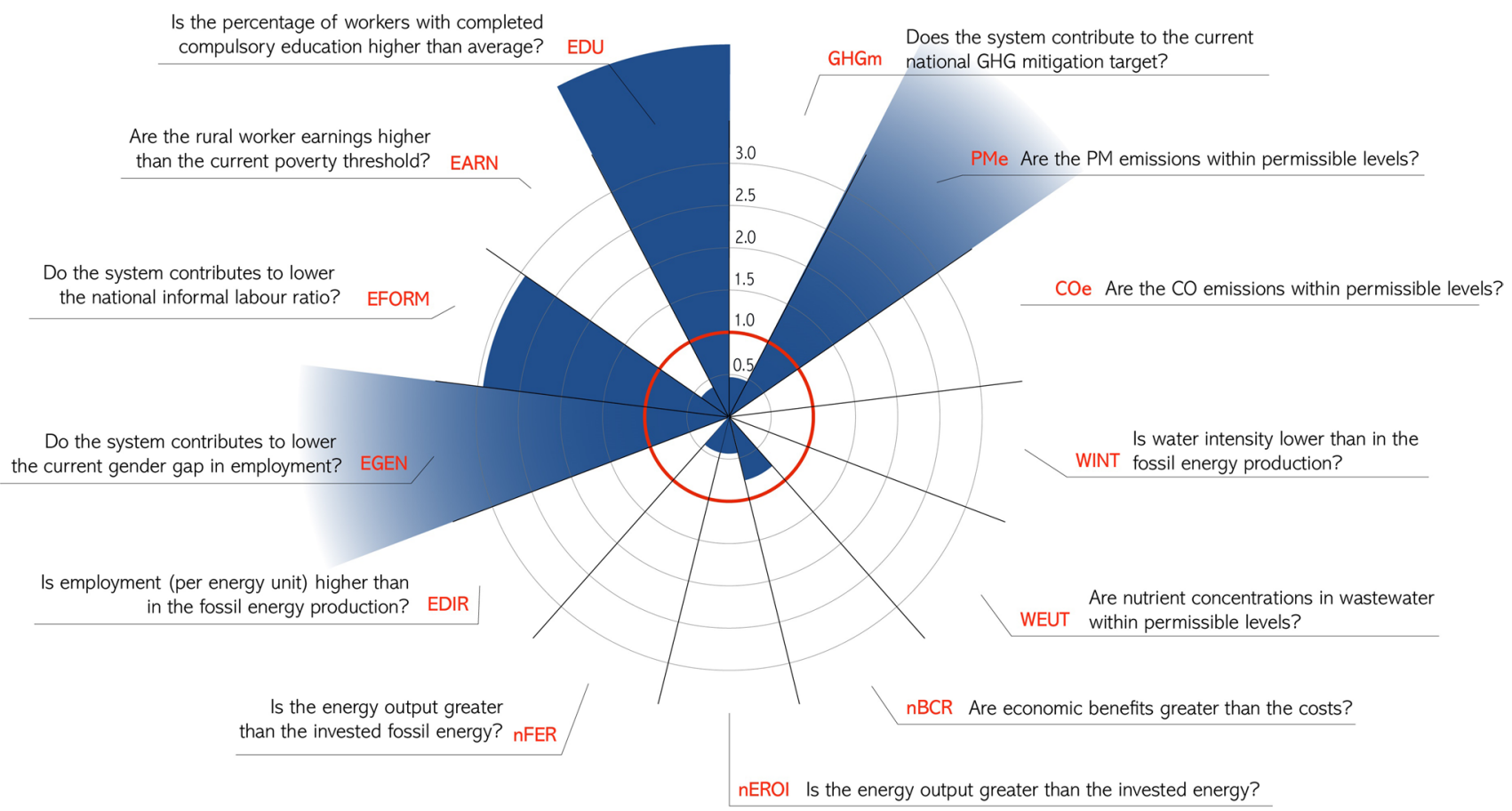

Fig. 4 Sustainability radar-plot of case study charcoal. The inner red circle represents the threshold value. Indication of unsustainability is depicted by segments that overpass the threshold

with generating the data and calculating the indicators? This section finishes with a critical analysis of the strengths and weaknesses of the framework and its indicators.

Note that the discussion on the specific indicator values in the case studies is available in the Supplementary Information (SI).

\section{The Results Are Easy to Understand and Communicate}

Figure 4 is the graphical representation of the results (numerical indicators) of the charcoal case in a single radial plot. The normalized scale in this setting allows for the quick identification of the indicators above the sustainability threshold (four in this case). It also highlights those indicators that have very undesirable values (bars exceeding the plot's scale, in this case EGEN, EDU, and PMe), and those having ideal or close to ideal values (very short or absent bars, like COe, WINT, WEUT, and EDIR). The multidimensional nature of the sustainability assessment is also explicit, as each indicator tells part of the story about the sustainability of the system under study. When interpreting the results, the threshold definitions should be kept in mind (Table 3). A common language interpretation of these thresholds has been added to Fig. 4 in the form of a question that each indicator can answer to.

Some indicators are straightforward in their meaning; particulate matter emissions (PMe), carbon monoxide emissions (COe), and water eutrophication (WEUT) are comparisons of a value against MPLs in environmental regulations; $\mathrm{nBCR}$, nEROI, and normalized fossil energy ratio (nFER) are simple indicators comparing two amounts: costs against benefits, energy output versus energy invested, etc. Others require understanding that the value is a comparison against a reference. While the concept of a reference system or business-as-usual scenario is commonplace in this type of evaluation, it requires an explicit explanation for the general public. That is, the case of water intensity (WINT) and EDIR (comparison against a fossil energy system with the same function as the SB). A third set of indicators compare the value of the SB system against national averages, such as educational level of workers (EDU), formal employment (EFORM), and gender equality among employees (EGEN), or against aspirational minimum values, such as average earnings per capita (EARN) (the poverty threshold) and GHGm (the NDC for GHG emissions). Finally, some indicators require understanding of technical data that is not intuitive for all. For example, EGEN refer to the "gender gap in employment," which is defined as the difference in percentage points between the proportion of men and women in work age that are indeed working. Finally, WINT is defined as water intensity, a technical term used to refer how much water is lost from natural reserves (consumptive water) to produce a unit of energy. In this summary, it was concluded that the results are easily understandable for people with basic exposure to environmental assessments, and five out 
Fig. 5 Values of the numerical indicators in the charcoal case distributed by sustainability dimensions. Red dots indicate values above the sustainability threshold (greater than one)

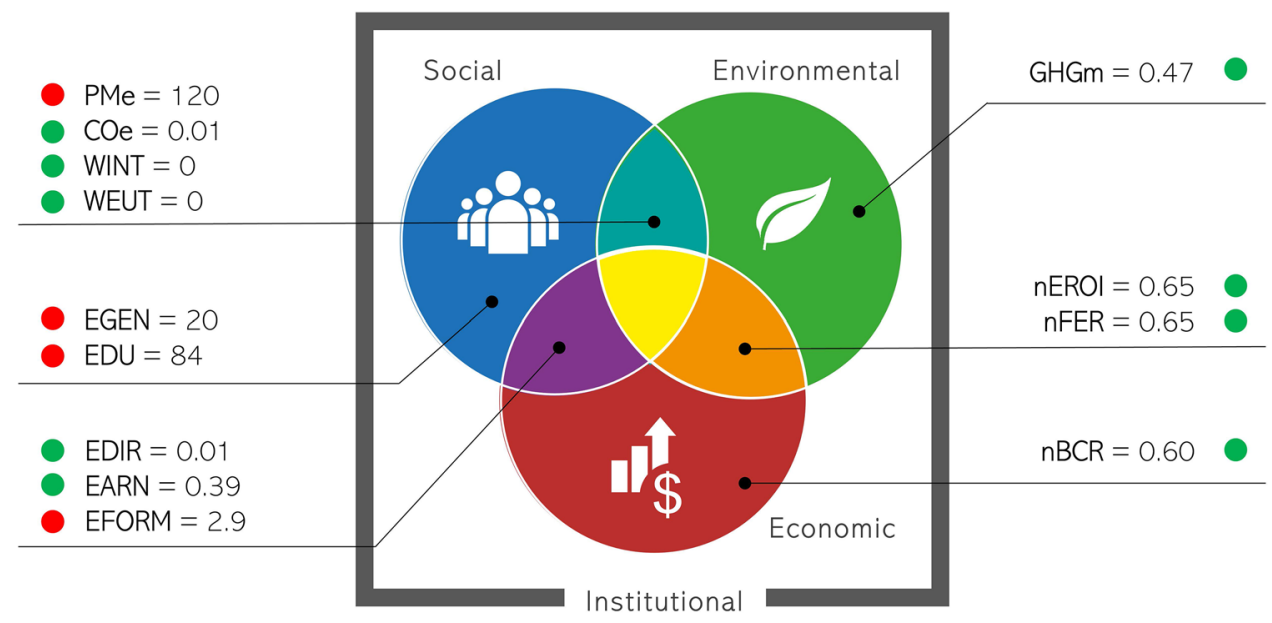

Fig. 6 Contribution by stage to the EDIR and EARN indicators in the bagasse case

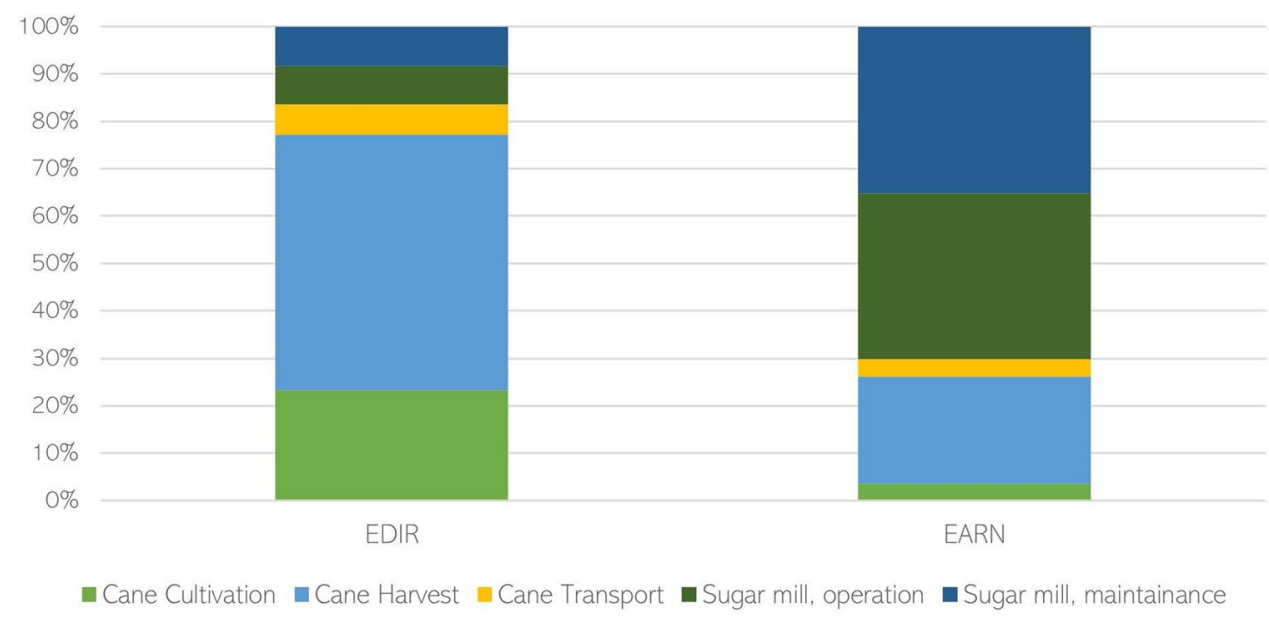

of 13 indicators may require a deeper explanation for the general public to understand their true meaning.

\section{The Framework Provides an Adequate Sustainability Assessment of SB Systems}

Judging from the literature review and the case studies, the framework successfully captures the main sustainability issues associated to SBs. It integrates information on all stages of the life cycle, and the four sustainability dimensions. It stands out from other frameworks in that it provides detailed information on the calculation procedures of the numerical indicators, allowing for a straightforward adoption. However, it was not possible to define numerical indicators to adequately describe biodiversity impacts, and institutional sustainability. Instead, a streamlined diagnosis tool was created for each aspect. This means that the environmental and institutional dimensions cannot be fully assessed using the normalized indicators, but need separate, more detailed assessment.
The explicit distribution of indicators among principles and criteria (Table 2), and among dimensions (Fig. 2), makes it possible to quickly identify the aspects that need more attention in the system. Figure 5 shows the results of the case study charcoal. At first glance, attention is drawn to the social dimension that encompasses all indicators with large values, i.e., EGEN, gender equity; EDU, educational level; EFORM, formal jobs; and PMe, PM emissions, related to potential health issues of users. Simultaneously, the number of jobs (EDIR) and earnings per capita of rural workers (EARN) are very favorable in this system, as well as all other indicators in the environmental and economic dimensions.

It is also possible to disaggregate the information required to calculate the indicators to identify the hot spots of the system. For example, in the charcoal case, the high concentration of PM in the use stage corresponds to the lack of emission control of the end-use device, in this case the charcoal grills, exposing the restaurant staff and customers to poor indoor-air quality. This type of analysis can be made graphical and quantitative, like in Fig. 6; in the Bagasse case, most jobs (EDIR) are created during the cultivation 
(22\%) and harvest (56\%) of the sugarcane, although the better paid jobs (EARN) are centralized in the other stages (in the sugar mill), where the permanent jobs are. Similar graphs can be produced for all indicators.

\section{The Framework is Applicable to a Diverse Range of SB Systems}

Another outstanding feature of this framework is its flexibility. Traditional SBs are usually not adequately described by existing frameworks; in turn, the applicability of this framework was demonstrated by assessing three dissimilar systems: charcoal (traditional semi-formal system, commercial heat, dedicated forest biomass), fuelwood (traditional informal system, residential heat, managed forest biomass), and bagasse (modern formal system, industrial electricity, residual biomass from agroindustry), although the evaluation of informal activities was a big challenge, as it will be discussed later. The framework was designed to assess all types of SB systems, trying to include the main sustainability aspects in national and international norms and regulations. Due to this starting point, some indicators were biased towards formal systems. In this article, informal systems are defined as those with no regulated markets and people not necessarily being employed by a company or business, or working informally (not paying taxes), or acquiring biomass only for their personal use.

Hence, the application of some indicators to the Fuelwood case study was difficult, since all activities are informal. This caused that EDIR, EFORM, and nBCR were not strictly applicable to this case. Thus, for the calculation of EDIR and EARN, it was necessary to define surrogate definitions of "employment" and "income," as explained in Section A.1.4. in the SI.

Although the operational definitions of thresholds (in the indicator's normalization) in this article were focused on Mexico, translating the values to other countries or regions is possible if a basic set of key data is available (water intensity of fossil energy generation, national regulations for PM, $\mathrm{CO}$, and wastewater emissions, formal employment rates, formal education statistics, and a poverty threshold). However, most of these may use international values as proxies, or thresholds from other countries in similar contexts.

Finally, the selected principles and criteria of the framework are applicable to all forms of bioenergy, not only SBs. However, before applying it to other bioenergy forms, it is necessary to identify which indicators are no longer important and which would need to be added. To cite one example, for assessing a biodiesel system, the PM emissions will not be an important issue. However, NOx emissions can be important, depending on the original feedstock; thus, a required modification would be substituting the PMe indicator for a NOx equivalent. Obviously, the threshold values for these new or modified indicators will need to be identified and operationalized in the respective normalization equations. It may be also possible that other criteria arise when adapting the framework to other bioenergy systems; for example, in the case of $1 \mathrm{G}$ biofuels, issues on land use change and competition would be important to consider. This, however, is outside the scope of this article.

\section{Data Availability and Accessibility Varies Depending on the Type of Evaluated System}

In the fuelwood case (and some stages of the charcoal case), a high degree of informality exists. This made the process of data gathering more difficult, as information is often scattered, not available, or non-existing. A big effort for doing interviews, field observations, and recognitions is necessary to collect some of the information, and still some inferences were needed to complete the datasets. This is especially true for indicators in the social and institutional dimensions. The environmental indicators were in general easier to calculate from internationally agreed emission factors or reports, although specific exceptions may arise. In formal systems, like in the bagasse case, data is generally available from the companies involved in the various stages. However, some indicators require sensitive data (personal data, salaries, informal jobs, national regulated environmental data) that companies may not be willing to share or allow publication. In some cases, confidentiality agreements may be enough to get access, but in others, this would be enough to restrict access to it. This is, however, a common issue in most comprehensive sustainability assessments, where participating companies need to be engaged on a transparent continuous improvement process of their operations.

Also, four indicators (nEROI, nFER, GHGm, WINT) require life cycle assessment (LCA) results for their calculation. Hence, their application inherits the benefits but also the drawbacks of LCAs, such as data and time intensity of the life cycle modeling.

\section{The Framework Is Not Designed to Compare Different SB Systems}

The normalized indicators are distance to target values, designed to simplify the interpretation and communication of the sustainability of a given system. If many scenarios of the same system are assessed, it is straightforward to compare all results in a single radial plot like Fig. 6 .

However, a direct comparison of different SB systems may not be entirely fair, and often not meaningful, since the boundaries, objectives, and scope; thresholds used; and other aspects may vary significantly across SB systems. For example, comparing the values of EDIR of the three case studies would lead to wrong conclusions, since jobs are not 
defined in the same manner in the fuelwood case (where there are no hired individuals), or in the bagasse case (where most are casual jobs). Similarly, when calculating WINT, the thresholds for heat-producing systems (fuelwood and charcoal) and the power-generating system (Bagasse) are different. While the normalized indicator adjusts to the same definition despite using different thresholds, comparing these two types of systems lacks practical meaning, because the produced energy is intended for different enduses and sectors. Another example is with the employment indicators (EDIR, EFORM, EDU, EGEN) that are defined to report on all employees in several stages (see Fig. 3), without using allocation in multiproduct systems. It was necessary to defined them like that to obtain values that are comparable with available thresholds. A consequence of this is that the results cannot be considered equivalent in dedicated energy systems (like fuelwood and charcoal) and multiproduct systems (like bagasse), where the jobs are not created with the sole purpose of energy generation.

\section{Managerial Insights of the Framework Results}

The results of this framework can provide a valuable overview of the sustainability of the production and use of SBs that can be applied internally by managers in the industry or externally by auditors, certification schemes, and government oversight. By using disaggregated sustainability indicators using life cycle thinking to many of them (see Fig. 3), it provides managers with clear indications of the hotspots in the production system, and signals to where improvements are needed. Given the distance-to-target results, it also allows estimating the marginal effort required to bring unfavorable indicators down to the sustainable region. Since trade-offs and synergies often exist between indicators, managers can use the framework to explore different scenarios and understand their cost and sustainability implications.

When comparing this framework to other methodologies for decision-making processes in the industrial sector [47, 48], it was clear from the theoretical and methodological point of view that their mathematical models, which present a single value solution to assess profit or SDG achievement level, can be complemented with our theoretical-empirical model, which is more compatible with the semi-informal nature of some systems, such as the fuelwood, and charcoal case studies. For example, decision-makers in the agri-food industry [47] may consider using their waste as an energy input in their process, after analyzing the sustainability trade-offs using this new framework.

\section{Critical Analysis of the Methodological Framework}

The strengths and weaknesses of the framework and indicators were discussed in a final workshop at the end of the development process. This summarizes the experiences of applying the final version of the framework to the three case studies. Overall, 11 strengths and 14 weaknesses were cited by at least one case study group, and Table 7 shows the most representative ones.

Most strengths and weaknesses were cited by only one or two case studies. This speaks of the general applicability of the indicators, and the need of discussing the results case by case, to reflect the particularities of the SB system under study. It also reinforces the idea of avoiding cross-system comparisons. Among the few coincidences in all three groups was the weakness of the time-consuming effort to estimate the institutional diagnosis ISD and the LCA-based indicators (GHGm, WINT, nEROI, nFER), and the strength of having a quantitative evaluation of most aspects. The easy estimation and interpretation of indicators was the strength with more mentions. The WINT and WEUT indicators were particularly easy to estimate in the fuelwood and charcoal cases, as there are not direct water inputs in the life cycle.

There was also agreement on the strengths of the ISD (tool specific to bioenergy and providing information regarding compliance) and the BID (not requiring fieldwork and focus on good practices). Cases involving companies (charcoal and bagasse) cited that information for $\mathrm{PMe}, \mathrm{COe}$, WEUT, nBCR, EFORM, EDU, and EARN may be sensitive data that companies may not be willing to share.

Regarding strengths and weaknesses specific to the case studies:

1. Fuelwood: emissions (GHGm, PMe, COe) and EGEN indicators had readily available data from literature, although the GHGm was not an important driver of the fuelwood use, so reporting it was judged of partial importance. Given the informal nature of the system, EDIR, EARN, and nBCR were not directly applicable, and required value judgments and assumptions to give a quantitative result (see Section A.1.4 in the SI). This also caused that EFORM was not applicable.

2. Charcoal: some emissions in the use stage (grills) was not available and were costly to obtain. Large variations of emissions were found due to the lack of standard designs of the charcoal grills. Also, PMe and COe by definition focus on the use stage, but in this case (traditional mound kilns), exposure to $\mathrm{PM}$ and $\mathrm{CO}$ of the workers is an important health hazard that cannot be captured by the PMe and the COe indicators without redefining their scope, and experimental measurements. Also, the semi-informal nature of the value chain requires specialized knowledge to appropriately do the BID and the ISD, and estimate $\mathrm{nBCR}$.

3. Bagasse: having an important industrial stage, including official regulations in the thresholds, was cited as a strength in GHGm, COe, WEUT, and the ISD. However, 
Table 7 Main strengths and weaknesses of the indicators in the framework. The blue, gray, and yellow cells represent the case studies fuelwood, bagasse, and charcoal, respectively. Black cells represent agreement in all three case studies

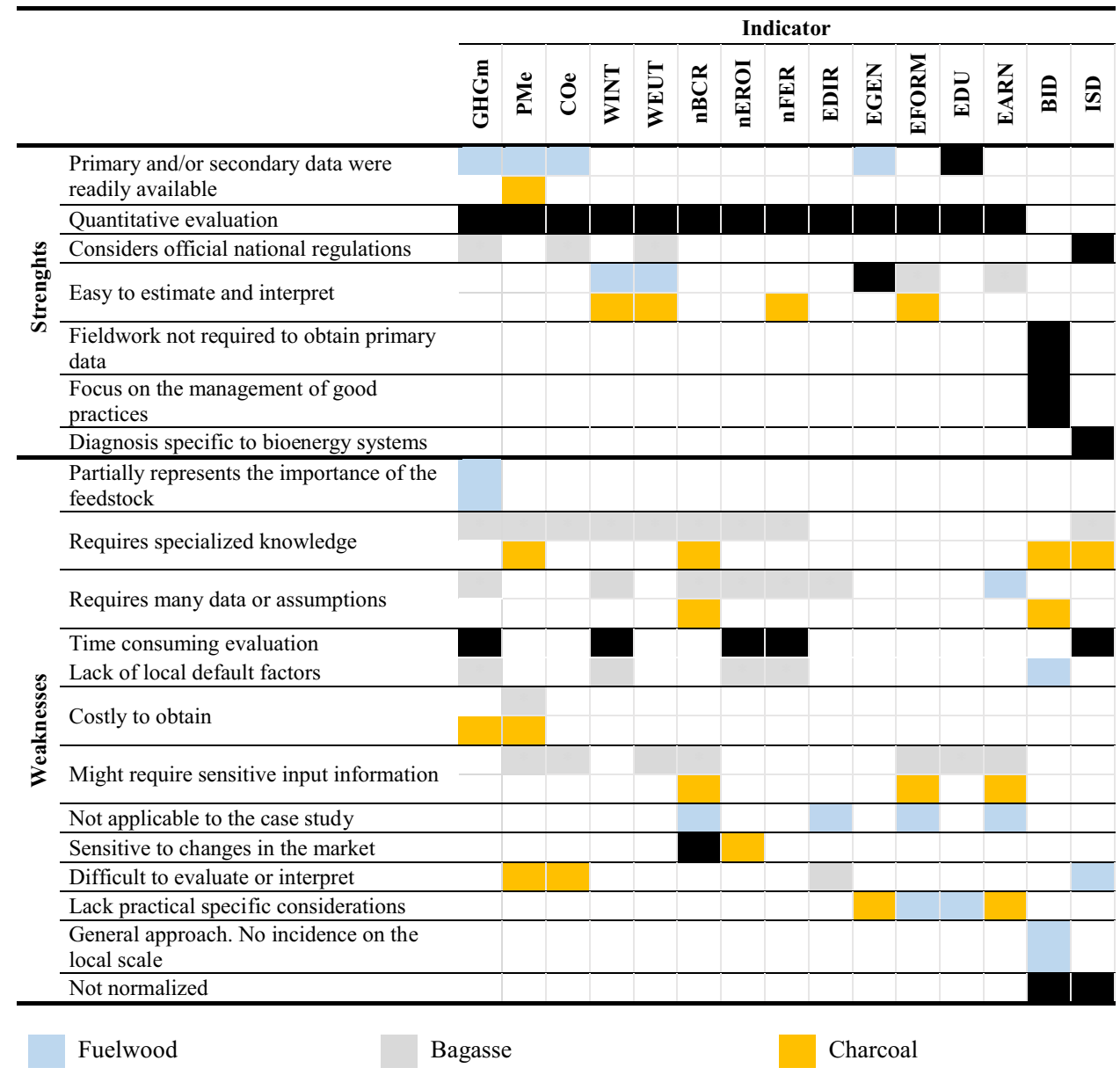

due to the multipurpose nature of the system, estimation of all environmental-related indicators required specialized knowledge to calculate them correctly, and many of them require making informed assumptions.

Form this analysis, the following key directions for improving the framework were identified:

a) Development of data collection forms to facilitate the data gathering stage for those indicators that require specialized knowledge.

b) Development of simple software tools associated with these questionnaires may reduce the computation work required to estimate some indicators, especially those depending on LCA.

c) The latter requires the construction of databases of emission factors and life cycle inventories for specific SB systems in Mexico.

d) Some indicators fell short to reflect informal systems, such as fuelwood. Given the importance of these systems in many Global South countries, further work is needed to adapt them or propose others that are more adequate.

\section{Conclusions}

A main feature of this new framework is that allows for a standalone, streamlined, but comprehensive sustainability assessment of SB systems. Its applicability to assess a broad range of both modern and traditional SB systems was demonstrated through three case studies, albeit the indicators related to employment lose meaning when describing informal systems, like traditional fuelwood. Although tested in the Mexican context, its applicability to other countries is straightforward if key national statistics and sustainability targets are available or can be approximated from surrogate data. The normalized framework should not be used to compare dissimilar systems; such comparisons render meaningless due to fundamental differences in the end-use energy (i.e., $1 \mathrm{MJ}$ of cooking heat vs $1 \mathrm{MJ}$ of industrial electricity), and the consequent adjustment on indicator thresholds. Acknowledged challenges for its application are the data intensiveness of the LCA-based indicators, and willingness of companies to share sensitive data, such as employment, salaries, and informality of operations. These, however, are shared drawbacks of all comprehensive sustainability assessments. A simple 
graphical tool was produced to make the numerical results easy to communicate to a wide audience.

Supplementary Information The online version contains supplementary material available at https://doi.org/10.1007/s12155-021-10365-2.

Acknowledgements We acknowledge the input of all participants in the Line 4 of the Cluster of Solid Biofuels, and the funding from the Mexican Council for Science and Technology (CONACYT) and the Mexican Secretariat of Energy through project Award Numbers 246911 "Clúster de biocombustibles sólidos para generación térmica y eléctrica" and 250014 "Clúster Biodiesel Avanzado."

Author Contribution All authors participated in structuring the framework. Specific contributions: operationalization of indicators and their normalization (J. C. S. R., F. S. N. P.). Formulation of indicators and state of the art (F. S. N. P., R. M., T. H. M.). Development and application of the economic indicator (M. E. S., G. G. A., F. M., J. I. S.). Project management (C. A. G., F. M., J. C. S. R.); funding acquisition (A. F. F. G., C. A. G., F. M.). Definition and analysis of case studies (fieldwork, data gathering and processing): fuelwood (R. D. M. B., A. F. F. G., A. L. M. G.), bagasse (C. A. G., R. M. G. A., R. C.), and charcoal (T. H. M., C. R. C. R.). Most writing and editing were done by J. C. S. R. and T. H. M.

Funding This work received support from two research projects funded by Mexican Council for Science and Technology (CONACYT) and the Mexican Secretariat of Energy (Fondo de Sustentabilidad Energética) Award Numbers 246911 "Clúster de biocombustibles sólidos para generación térmica y eléctrica" and 250014 "Clúster Biodiesel Avanzado."

Consejo Nacional de Ciencia y Tecnología,246911,250014

Data Availability The datasets generated are property of the institutions that generated them and may be made available on reasonable request through the Solid Biofuels Cluster.

Code Availability Not applicable.

\section{Declarations}

Ethics Approval (Include Appropriate Approvals or Waivers) Review of the methodological approach of the study by an official ethics committee was not required by our institutions or the granting agency. Nevertheless, the study abided to standard ethical practice of working with human subjects and being granted access to sensitive industry information.

Consent to Participate Verbal informed consent was obtained from all individuals who participated in the study. Anonymity has been granted to all participants (and industries) who wished to stay anonymous.

Consent for Publication All authors have given their consent for publication of this article. There is no need for consent from any other authors.

Competing interests The authors have no conflicts of interest or competing interests to declare that are relevant to the content of this article.

\section{References}

1. Bildirici ME (2013) Economic growth and biomass energy. Biomass Bioenergy 50:19-24. https://doi.org/10.1016/j.biombioe. 2012.09.055

2. International Renewable Energy Agency (2021) World Energy Transitions Outlook: $1.5^{\circ} \mathrm{C}$ pathway. International Renewable Energy Agency, Abu Dhabi

3. Buytaert V, Muys B, Devriendt N et al (2011) Towards integrated sustainability assessment for energetic use of biomass: a state of the art evaluation of assessment tools. Renew Sustain Energy Rev 15:3918-3933. https://doi.org/10.1016/j.rser.2011. 07.036

4. Bilgili F, Koçak E, Bulut Ü, et al (2016) Can biomass energy be efficient policy tool for sustainable development? Renew Sustain Energy Rev 71:16. 10.1016

5. Angelakoglou K, Gaidajis G (2015) A review of methods contributing to the assessment of the environmental sustainability of industrial systems. J Clean Prod 108:725-747. https://doi. org/10.1016/j.jclepro.2015.06.094

6. Kleeberg K, Schneider K, Nippa M (2015) Methods for measuring and evaluating sustainability: state-of-the art, challenges, and future developments. In: Handbook of Clean Energy Systems. John Wiley \& Sons, Ltd, Chichester, UK, pp 1-26

7. Liew WH, Hassim MH, Ng DKS (2014) Review of evolution, technology and sustainability assessments of biofuel production. J Clean Prod 71:11-29. https://doi.org/10.1016/j.jclepro. 2014.01.006

8. Jin E, Sutherland JW (2016) A proposed integrated sustainability model for a bioenergy system. Procedia CIRP 48:358-363. https://doi.org/10.1016/j.procir.2016.03.159

9. Martín M (2016) RePSIM metric for design of sustainable renewable based fuel and power production processes. Energy 114:833-845. https://doi.org/10.1016/j.energy.2016.08.031

10. Valdez-Vazquez I, Gastelum CRS, Escalante AE (2017) Proposal for a sustainability evaluation framework for bioenergy production systems using the MESMIS methodology. Renew Sustain Energy Rev 68:360-369

11. GBEP (2011) Global Bioenergy Partnership Sustainability Indicators for Bioenergy. http://www.cleanenergyministerial. org/Portals/2/pdfs/The_GBEP_Sustainability_Indicators_for_ Bioenergy_FINAL.pdf

12. RSB (2016) RSB principles and criteria. In: RSB Princ. criteria. https://rsb.org/wp-content/uploads/2017/04/RSB-STD-01-001_ Principles_and_Criteria-DIGITAL.pdf. Accessed 22 Nov 2021

13. Kituyi E (2004) Towards sustainable production and use of charcoal in Kenya: exploring the potential in life cycle management approach. J Clean Prod 12:1047-1057

14. Rose S, Remedio E, Trossero MA (2009) Criteria and indicators for sustainable woodfuels. In: Criteria Indic. Sustain. woodfuels. https://energypedia.info/images/1/1a/2010_FAO_susta inable_woodfuel_guidelines-1-.pdf. Accessed 23 Nov 2021

15. Kurka T, Blackwood D (2013) Participatory selection of sustainability criteria and indicators for bioenergy developments. Renew Sustain Energy Rev 24:92-102. https://doi.org/10. 1016/j.rser.2013.03.062

16. Suwelack K, Wüst D (2015) An approach to unify the appraisal framework for biomass conversion systems. Biomass Bioenergy 83:354-365. https://doi.org/10.1016/j.biombioe.2015.10.012

17. Martín-Gamboa M, Dias LC, Quinteiro P, et al (2019) Multicriteria and life cycle assessment of wood-based bioenergy alternatives for residential heating: a sustainability analysis. Energies 12https://doi.org/10.3390/en12224391

18. McBride AC, Dale VH, Baskaran LM et al (2011) Indicators to support environmental sustainability of bioenergy systems. Ecol 
Indic 11:1277-1289. https://doi.org/10.1016/j.ecolind.2011.01. 010

19. United Nations (2020) Global indicator framework for the sustainable development goals and targets of the 2030 agenda for sustainable development. In: Work Stat. Comm. Pertain. to 2030 Agenda Sustain. Dev. https://unstats.un.org/sdgs/indicators/Global Indicator Framework after 2020 review_Eng.pdf. Accessed 23 Nov 2021

20. OECD (2008) OECD Key environmental indicators. In: Key Environ. Indic. https://www.oecd.org/env/indicators-modelling-outlo oks/37551205.pdf. Accessed 23 Nov 2021

21. Barnett B (2016) An evaluation of the UK's use of SFM standards to procure solid woody biomass for electricity generation using sustainable bioenergy criteria. Biofuels-Uk 7:1-11. https://doi. org/10.1080/17597269.2015.1118775

22. Vera IA, Langlois LM, Rogner HH et al (2005) Indicators for sustainable energy development: an initiative by the International Atomic Energy Agency. Nat Resour Forum 29:274-283. https:// doi.org/10.1111/j.1477-8947.2005.00140.x

23. Dale BE, Ong RG (2014) Design, implementation, and evaluation of sustainable bioenergy production systems. Biofuels, Bioprod Biorefining 8:487-503. https://doi.org/10.1002/bbb.1504

24. Sacramento-Rivero JC (2012) A methodology for evaluating the sustainability of biorefineries: framework and indicators. Biofuels, Bioprod Biorefining 6:32-44. https://doi.org/10.1002/bbb.335

25. Steffen W, Richardson K, Rockström J, et al (2015) Planetary boundaries: guiding human development on a changing planet. Science (80- ) 347:1259855. https://doi.org/10.1126/science. 1259855

26. Bjorn A, Chandrakumar C, Boulay AM, et al (2020) Review of life-cycle based methods for absolute environmental sustainability assessment and their applications. Environ Res Lett 15https://doi. org/10.1088/1748-9326/ab89d7

27. Murphy DJ, Hall CAS, Dale M, Cleveland C (2011) Order from chaos: a preliminary protocol for determining the EROI of fuels. Sustainability 3:1888-1907. https://doi.org/10.3390/su3101888

28. Rana RL, Lombardi M, Giungato P, Tricase C (2020) Trends in scientific literature on energy return tatio of renewable energy sources for supporting policymakers. Adm Sci 10:21. https://doi. org/10.3390/admsci10020021

29. Wei M, Patadia S, Kammen DM (2010) Putting renewables and energy efficiency to work: how many jobs can the clean energy industry generate in the US? Energy Policy 38:919-931. https:// doi.org/10.1016/j.enpol.2009.10.044

30. Serrano-Medrano M, García-Bustamante C, Berrueta VM, et al (2018) Promoting LPG, clean woodburning cookstoves or both? Climate change mitigation implications of integrated household energy transition scenarios in rural Mexico. Environ Res Lett 13https://doi.org/10.1088/1748-9326/aad5b8

31. Murphy DJ, Hall CAS, Powers B (2011) New perspectives on the energy return on (energy) investment (EROI) of corn ethanol. Environ Dev Sustain 13:179-202. https://doi.org/10.1007/ s10668-010-9255-7

32. Dale VH, Efroymson RA, Kline KL et al (2013) Indicators for assessing socioeconomic sustainability of bioenergy systems: a short list of practical measures. Ecol Indic 26:87-102. https://doi. org/10.1016/j.ecolind.2012.10.014

33. Siebert A, Bezama A, O'Keeffe S, Thrän D (2018) Social life cycle assessment indices and indicators to monitor the social implications of wood-based products. J Clean Prod 172:40744084. https://doi.org/10.1016/j.jclepro.2017.02.146

34. Rivero JCS, Eastmond-Spencer A, García JB, Navarro-Pineda FS (2016) A three-dimensional sustainability evaluation of jatropha plantations in Yucatan, Mexico. Sustain 8https://doi.org/10.3390/ su8121316

35. Spangenberg JH (2016) The Corporate Human Development Index CHDI: a tool for corporate social sustainability management and reporting. J Clean Prod 134:414-424

36. Sundström A, Ahmadi Z, Mickelsson K (2019) Implementing social sustainability for innovative industrial work environments. Sustainability 11:3402

37. Vaidya A, Mayer AL (2016) Criteria and indicators for a bioenergy production industry identified via stakeholder participation. Int J Sustain Dev World Ecol 4509:1-15. https://doi.org/10.1080/ 13504509.2015.1135830

38. Iribarren D, Martín-Gamboa M, O’Mahony T, Dufour J (2016) Screening of socio-economic indicators for sustainability assessment: a combined life cycle assessment and data envelopment analysis approach. Int J Life Cycle Assess 21:202-214. https:// doi.org/10.1007/s11367-015-1002-8

39. Sinclair P, Cohen B, Hansen Y et al (2015) Stakeholder engagement within the sustainability assessment of bioenergy: case studies in heat, power and perennial and annual crops from the UK. Biomass Bioenergy 73:11-22. https://doi.org/10.1016/j.biombioe. 2014.11.017

40. Becerril J, Ortiz R, Albornoz L (2012) Maquiladora factories and household income in Yucatan. Probl Desarro 43:135-160

41. Lattimore B, Smith CT, Titus BD et al (2009) Environmental factors in woodfuel production: opportunities, risks, and criteria and indicators for sustainable practices. Biomass Bioenergy 33:1321-1342

42. David Cooper H, Noonan-Mooney K (2013) Convention on biological diversity. Encycl Biodivers Second Ed 306-319https://doi. org/10.1016/B978-0-12-384719-5.00418-4

43. Pfahl S (2005) Institutional sustainability Int J Sustain Dev 8:80-96

44. Berrueta Soriano VM (2007) Energy assessment of the performance of wood cooking devices. National Autonomous University of Mexico

45. Berrueta VM, Serrano-Medrano M, García-Bustamante C et al (2017) Promoting sustainable local development of rural communities and mitigating climate change: the case of Mexico's Patsari improved cookstove project. Clim Change 140:63-77. https://doi. org/10.1007/s 10584-015-1523-y

46. Rincón LE, Becerra LA, Moncada J, Cardona CA (2014) Technoeconomic analysis of the use of fired cogeneration systems based on sugar cane bagasse in south eastern and mid-western regions of Mexico. Waste and Biomass Valorization 5:189-198. https:// doi.org/10.1007/s12649-013-9224-0

47. Sepehri A, Mishra U, Sarkar B (2021) A sustainable production-inventory model with imperfect quality under preservation technology and quality improvement investment. J Clean Prod 310:127332. https://doi.org/10.1016/j.jclepro.2021.127332

48. AlArjani A, Modibbo UM, Ali I, Sarkar B (2021) A new framework for the sustainable development goals of Saudi Arabia. J King Saud Univ - Sci 33:101477. https://doi.org/10.1016/j.jksus. 2021.101477

Publisher's Note Springer Nature remains neutral with regard to jurisdictional claims in published maps and institutional affiliations. 